\title{
Development of Plasmodium falciparum Protease Inhibitors in the Past Decade (2002-2012)
}

\author{
B. Pérez ${ }^{1}$, C. Teixeira*,1,2, J.R.B. Gomes ${ }^{2}$ and P. Gomes ${ }^{1}$
}

${ }^{1}$ Centro de Investigação em Química da Universidade do Porto, Departamento de Química e Bioquímica, Faculdade de Ciências, Universidade do Porto, R. do Campo Alegre, 687, P-4169-007 Porto, Portugal; ${ }^{2}$ CICECO, Departamento de Química, Universidade de Aveiro, Campus Universitário de Santiago, 3810-193 Aveiro, Portugal

\begin{abstract}
New drug targets for the development of antimalarial drugs have emerged after the unveiling of the Plasmodium falciparum genome in 2002. Potential antimalarial drug targets can be broadly classified into three categories according to their function in the parasite's life cycle: (i) biosynthesis, (ii) membrane transport and signaling, and (iii) hemoglobin catabolism. The latter plays a key role, as inhibition of hemoglobin degradation impairs maturation of bloodstage malaria parasites, ultimately leading to remission or even cure of the most severe stage of the infection. Intraerythrocytic Plasmodia parasites have limited capacity to biosynthesize amino acids which are vital for their growth. Therefore, the parasites obtain those essential amino acids via degradation of host cell hemoglobin, making this a crucial process for parasite survival. Several plasmodial proteases are involved in hemoglobin catabolism, among which plasmepsins and falcipains are well-known examples. Hence, development of $P$. falciparum protease inhibitors is a promising approach to antimalarial chemotherapy, as highlighted by the present review which is focused on the Medicinal Chemistry research effort recorded in the past decade in this particular field.
\end{abstract}

Keywords: Plasmodium falciparum, hemoglobin catabolism, plasmepsin, falcipain, falcilysin, aminopeptidase, proteases, antimalarial.

\section{INTRODUCTION}

Malaria is one of the most threatening infectious diseases that mainly affects the world's poorest countries in tropical areas [1]. Approximately $40 \%$ of the world population lives at risk of this disease and this constitutes a large burden on the health and economic development of low-incomes countries [1-3]. Although the World Malaria Report 2011 showed that there has been significant and durable progress in battling this disease, emergence of parasite resistance to antimalarial medicines remains a threat to this continued stride toward the reduction of malaria cases in the world. There are five species of Plasmodium which cause malaria in human. Those species are $P$. ovale, $P$. malariae, $P$. knowlesi $[4,5]$, $P$. vivax and $P$. falciparum $(P f)$, the latter being the deadliest $[6,7]$. Malaria is transmitted by a female infected Anopheles mosquito that harbors $P f$ sporozoites in its salivary glands; by biting a human, the mosquito injects those sporozoites into the blood-stream, and they are then carried to the liver to develop into merozoites, which subsequently are released into the blood stream invading host red blood cells and multiplying asexually as trophozoites. Some erythrocytic parasites develop into male and female gametocytes, the only forms able to infect other mosquitoes and there reproduce sexually, permitting completion of the life cycle [2].

\footnotetext{
*Address correspondence to this author at the Centro de Investigação em Química da Universidade do Porto, Departamento de Química e Bioquímica, Faculdade de Ciências, Universidade do Porto, R. do Campo Alegre, 687, P-4169-007 Porto, Portugal; Tel: +351 234401 423; Fax: +351 234 401 470; E-mail: ca.teixeira@ua.pt
}

Currently, there are drugs targeting different stages in the malaria life cycle such as chloroquine $\mathbf{1}$, artemisinin $\mathbf{2}$, and primaquine $\mathbf{3}$ (Fig. 1). However, the increasing spread of parasite strains resistant to currently used antimalarials has put enormous pressure on public health systems to introduce new treatments [8]. Given that the hope for a long-lasting vaccine against malaria is yet an unmet goal, it appears that control of the disease has to rely mostly on chemotherapy in the foreseeable future [9].<smiles>CCN(CC)CCCC(C)Nc1ccnc2cc(Cl)ccc12</smiles>
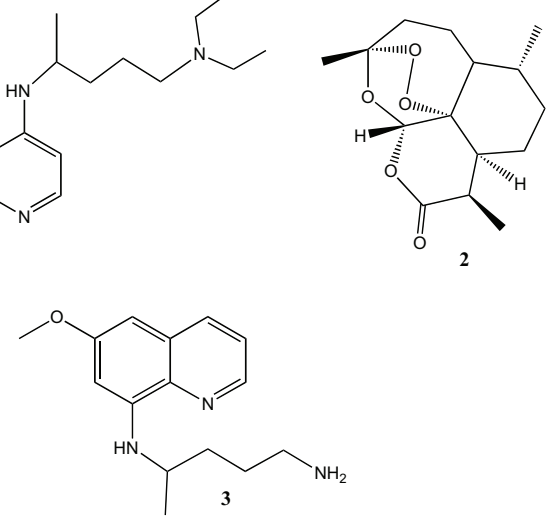

Fig. (1). Structure of known antimalarials: chloroquine (1), artemisinin (2), and primaquine (3).

Since the unveiling of the $P f$ genome, a decade ago, new targets for development of antimalarial drugs have arisen [10]. Antimalarial targets can be broadly classified into three 
categories according to their function in the parasite's life cycle: (i) biosynthesis, (ii) membrane transport and signaling, and (iii) hemoglobin catabolism. To the first target category belong $P f$ enzymes in charge of generating nutrients required for malaria parasite growth. For instance, there are different biosynthesis pathways today used as targets for the discovery of antimalarial drugs such as the folate biosynthesis pathway [11-13]. The second target category includes pathways which mediate the uptake of nutrients into cells and the generation and maintenance of transmembrane electrochemical gradients, for instance, the plasmodial surface anion channel (PSAC) [14-16]. Other examples which fall within this target category are enzymes whose substrates are involved in intracellular signal transduction, for instance, farnesyltransferase [17-19]. Finally, targets within the third target category play an essential role in the development of intraerythrocytic malaria parasites. Since the digestion of hemoglobin is presumably an essential catabolic function performed by the blood stage parasites, the proteases participating in this pathway have been proposed as targets for the development of novel antimalarial drugs [20-22]. This review will mainly focus on such proteases and their inhibitors developed in the past decade.

\section{HEMOGLOBIN CATABOLISM}

During the intraerythrocytic development of the asexual stages of $P f$, the parasite inhabits a parasitophorous vacuole (PV) formed inside the red blood cell (RBC); host cell hemoglobin is endocytosed by the PV and transported to an acidic compartment known as the parasite's food vacuole (FV). Within the FV, proteases degrade most of the host hemoglobin to free amino acids that can then be incorporated into newly synthesized proteins [23] and used to modulate the osmotic status of the host cell $[24,25]$. In addition, removal of hemoglobin also frees up space within the RBC for parasite replication [26]. Early in the degradative pathway, free heme is released and oxidized from the ferrous $\left(\mathrm{Fe}^{2+}\right)$ state to the ferric $\left(\mathrm{Fe}^{3+}\right)$ hematin. Both heme and hematin are potentially toxic to the parasite [27]. To counter this, the parasite has evolved a detoxification system resulting in the formation of the hemozoin pigment, an inert crystalline $\beta$ hematin polymer $[28,29]$. Antimalarial 4-amino-quinolines, such as chloroquine (1, Fig. 1), appear to function by disrupting this sequestration, leading to an accumulation of toxic heme products [30].

Studies suggest that the proteases in charge of hemoglobin degradation are essential for the parasite growth since the parasite has limited ability for de novo biosynthesis of the amino acids needed for its own proteins. It has been shown that $P f$ can also obtain amino acids exogenously, as parasites can survive in media supplemented only with isoleucine, an amino acid not contained in hemoglobin; yet, in the absence of an exogenous amino acids source, the parasite can solely rely on hemoglobin degradation to obtain most of the required amino acids [31]. Moreover, it has been clearly shown that $P f$ utilizes hemoglobin as an amino acid source for protein synthesis, as amino acids from hemoglobin degradation have been detected in parasite's proteins, and in vitro experiments where hemoglobin digestion has been impaired revealed that parasite development and morphology were significantly affected [32].

Extensive study of this protease cascade has resulted in the model outlined in (Fig. 2) for hemoglobin degradation. There is evidence that the degradative enzymes function in a semi-ordered pathway [30], with aspartyl proteases, being the first to participate in this proteolytic pathway by making the initial cleavage in intact hemoglobin. Subsequent degradations of globin into small peptides chains are carried by cysteine proteases, metalloprotease falcilysin (FLN), and dipeptidyl amino peptidase 1 (DPAP1) [33]. Following, the small peptides are transported to the parasite cytoplasm where they are terminally degraded to amino acids by exopeptidases (Fig. 2) [33].

From the above, it is understandable that proteases involved in this catabolic pathway have become of substantial interest for the malaria research community. Certain inhibitors for these enzymes have been tested in in vitro experiments and found to block $P f$ growth and its expansion to other erythrocytes [35-37]. Therefore, the search for potent inhibitors of these proteases has become a new strategy for developing new antimalarial drugs.

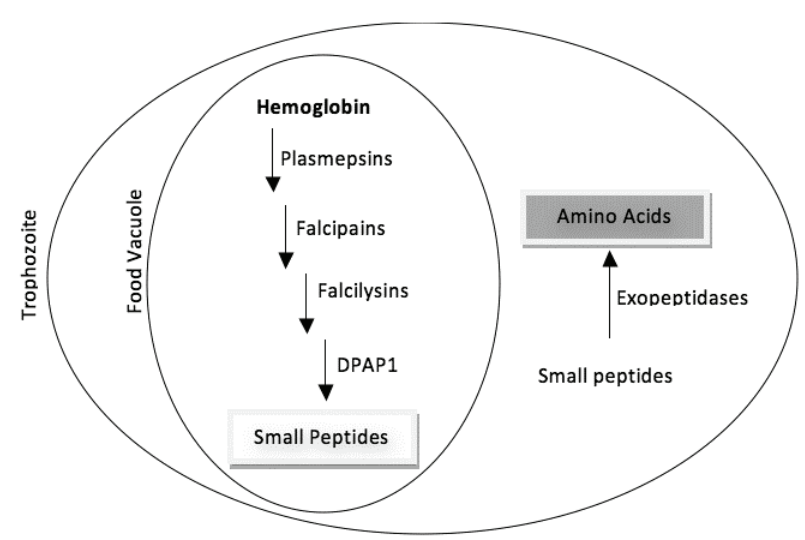

Fig. (2). Proteolytic cascade in hemoglobin degradation by $P f$ parasites. For a more detailed explanation refer to: http://priweb.cc.huji. ac.il/malaria/FramHemoglobindigest.html and see ref [34].

\subsection{Aspartyl Proteases (Plasmepsins)}

$P f$ contains at least 10 aspartyl proteases, known as plasmepsins: plasmepsins I, II, and IV-X, and histidine aspartic protease (HAP). The precise role of each of the plasmepsins in the parasite metabolism is not clear. To date, the most extensively studied plasmepsins are plasmepsin I (Plm I; EC number: 3.4.23.38), plasmepsin II (Plm II; EC number: 3.4.23.39), plasmepsin IV (Plm IV; EC number: 3.4.23.B14) and HAP. These aspartyl proteases are expressed during the erythrocytic stage of the parasite [38], have all been shown to be directly involved in the process of hemoglobin degradation $[38,39]$, and have all been characterized structurally [40]. High levels of sequence homology (60\%-70\%) [41] are observed between Plm I, II, IV, and HAP, which also lies in a cluster on the same gene [39]. Compared to Plm II, the binding site regions of Plm I, IV, and HAP show 84\%, 68\%, and $39 \%$ identity, respectively [42]. 
Plm I and Plm II catalyze the initial step in the breakdown of hemoglobin by the parasite by making the first cleavage of hemoglobin between Phe33 and Leu34 of the $\alpha$-chain to generate globin and free heme $[38,39]$. In addition to its participation in hemoglobin degradation, the interest in Plm IV is also motivated by the fact that it is the only plasmepsin located in the FV of $P f$ which has orthologs in the other Plasmodium species infecting human [41]. HAP is unique in the sense that it has a histidine in the place of the first canonical aspartic acid. Whether this results in an aspartic- or serine-proteaselike mechanism has been subject of discussion [43]. Computational predictions indicate that only the aspartic acid (Asp214) is directly involved in catalysis, while the histidine residue (His34) provides critical stabilization along the cleavage [44]. Recent knock-out studies revealed that single, double, and even triple knock-outs of FV plasmepsins are viable, suggesting that multiple plasmepsins must be targeted to produce antiparasitic effects [45]. This also indicates that there is a high number and functional redundancy of plasmepsins in the hemoglobin pathway. However, it has been shown that Plm inhibitors significantly attenuated parasitemia both in culture and in animal models [46].

As the crystal structure of Plm II was the first one to be publicly available, most research focused on the development of Plm II inhibitors. Plm II contains 329 amino acids and its binding cleft, also known as the catalytic dyad, is constituted by Asp34 and Asp214, which are bridged by a water molecule [47]. Hydrolysis of the peptide bond between hemoglobin's Phe33 and Leu34 takes place once Asp214 abstracts one of the protons from the water molecule, and generates two peptide chains (Fig. 3) [35, 47]. The cleavage mechanism concludes when the peptide products leave the active site and the water bridge between Asp34 and Asp214 is regenerated.

Plm I and II have a 73\% sequence homology suggesting that both enzymes can be inhibited by related molecules. Therefore, Plm I and II have become the main targets of most plasmepsin inhibitors developed as potential antimalarial drugs. Yet, these plasmepsins show high structural similarity with human cathepsin $\mathrm{D}$, which makes selectivity an important factor to take into account when designing suitable inhibitors.

Well known HIV-1 aspartyl protease inhibitors, such as ritonavir, indinavir, nelfinavir, lopinavir, saquinavir, ata- zanavir and amprenavir, were also found to inhibit $P f$ aspartyl proteases and the development of parasites at pharmacologically relevant concentrations [48]. All of these inhibitors undergo non-covalent interactions with the proteases and share key structural structures for the inhibition of aspartyl proteases, which is a hydroxyl or hydroxyl-like moiety that coordinates to the catalytic dyad and mimics the transition state for peptide bond hydrolysis. The $(S)$-hydroxyl group displaces the water molecule from the catalytic site and forms a hydrogen bond with Asp [49, 50]. Like these HIV-1 aspartyl protease inhibitors, most Plm I and II inhibitors mimic the tetrahedral intermediate formed during the aspartyl protease catalysis. There are several transition state analogue cores used for the design of Plm inhibitors [35, 51-65], but the most important include the statine core $[54,56,57$, $64]$, the reversed-statine core [53, 54], or a hydroxyethylamine motif (Fig. 4) [56, 61, 62].

Studies using encoded combinatory libraries based on the statine core structure 4 (Fig. 5) allowed determining that $\beta$ branched side chains are preferred in P2 and hydrophobic side chains as phenyl or isobutyl in P1. In addition, P2 and P3 substituents impart selectivity in Plm II inhibitors (Fig. 5) $[66,67]$. One advantage of this type of inhibitors is that they don't cross inhibit other proteases such as serine-, cysteine-, or metallo-proteases [68].

Recently reported statine-based inhibitors include the one found by Bosisio and co-workers [64]. They coupled a series of statine-based inhibitors with primaquine 3 and found low nanomolar inhibitors of Plm II with $\mathrm{IC}_{50}$ between 0.59 to 400 $\mathrm{nM}$ and low micromolar activity in vitro against $P f$, the best of which (5) is shown in (Fig. 6). A direct correlation between the compounds' activity against Plm II and the in vitro parasite growth suggested that the main mechanism of these inhibitors was Plm II inhibition and consequently, the digestion of hemoglobin that is essential for $P f$ survival as stated before. Compound with the linker derived from a succinic acid was the least active of the series which is in agreement with the finding suggesting that an aromatic substituent is preferred in P3 for Plm II inhibition [66]. The introduction of an aromatic ring as a linker in general structure $\mathbf{6}$ increased the activity as expected and compounds with a naphthyl were more active against Plm II. Still, there was not significant increase of the resulting derivatives against parasite growth. Compound 5 was considerably more active against the enzyme and parasite growth with $\mathrm{IC}_{50} 0.59 \mathrm{nM}$ on in vitro in-

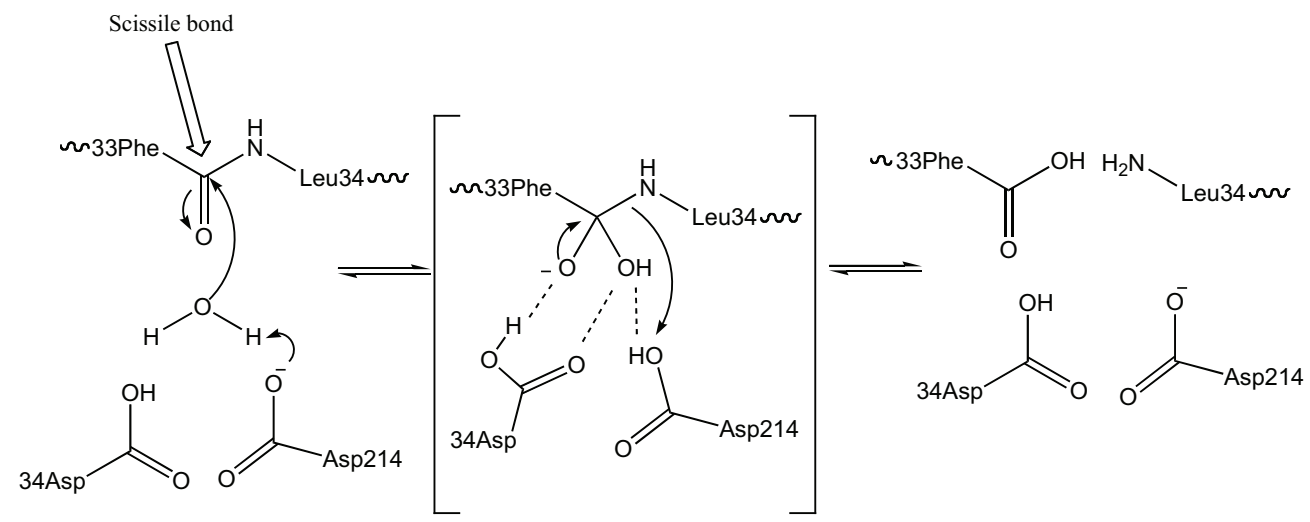

Fig. (3). Schematic mechanism of hemoglobin cleavage by Plm II. 


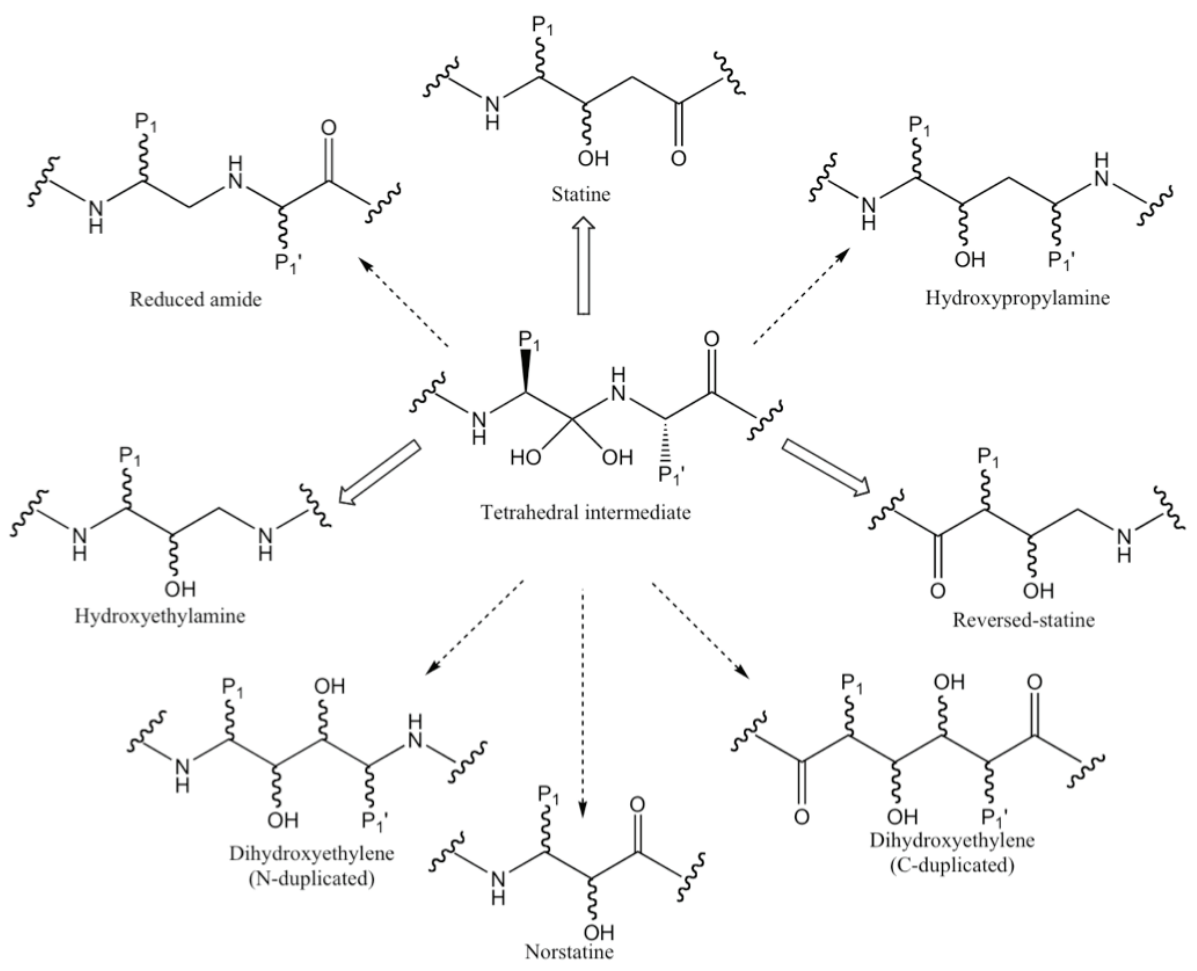

Fig. (4). Transition-state mimicking groups in peptidomimetic plasmepsin inhibitors: reduced amine [52, 59], statine [54, 56, 57, 64], hydroxypropylamine [51], reversed-statine [53, 54], dihydroxyethylene ( $C$ - and $N$-duplicated) [35, 55, 63], norstatine [58, 60, 65], and hydroxyethylamine [56, 61, 62].

hibition of $\mathrm{P} \operatorname{lm} \mathrm{II}$, and $\mathrm{IC}_{50}$ of $0.4 \mu \mathrm{M}$ on in vitro inhibition of growth of Pf D10 [64]. Additional studies were done to verify the dual-action of compound $\mathbf{5}$. The products of the hydrolysis of Lys-Leu peptide bond in compound $\mathbf{5}$ were assessed as inhibitors of the parasite development and Plm II activity. Even though such products were both active against parasite growth in the micromolar range, compound's activity against the parasite development was found to be mainly due to Plm II inhibition.

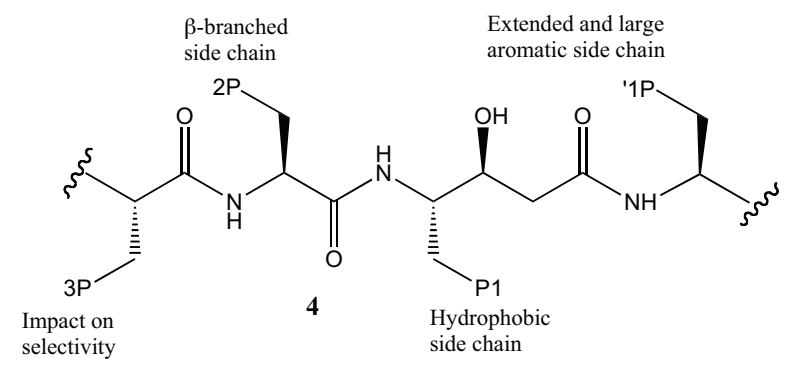

Fig. (5). General structure requirements for Plm I and Plm II inhibitors based on the statine core.

Samuelsson and co-workers reported [54] a series of statine-reversed core inhibitors of Plm I and Plm II. The best inhibitor 7 of the series (Fig. 7) exhibits $K_{\mathrm{i}}$ values of $250 \mathrm{nM}$ and $1.4 \mu \mathrm{M}$ for Plm I and II, respectively. To increase affinity to both plasmepsins a benzyl group was added to the $N$ terminus to interact with the $\mathrm{S} 1$ ' pocket of the proteases. Furthermore, a hydrazine moiety was inserted to allow flexibility to the benzyl substituent in the $N$-terminus to better fit in the S1' pocket. All the compounds were tested against $\mathrm{Plm}$ I and II activity. From the inhibition results it can be inferred that the N-benzyl derivatives were almost inactive whereas the aza-benzyl derivatives promote the inhibition of both plasmepsins. Also, the presence of the carboxybenzyl group in the P2' position seems to increase the activity of the compounds. Samuelsson and co-workers [54] also reported that the basic piperidine- and pyridine-substituents are present in the majority of the potent inhibitors, for instance, see compound 7.

In 2003, Nöteberg and co-workers [61] reported a series of compounds, including a basic hydroxyethylamine transition state isostere, designed and synthesized as inhibitors of Plm I and Plm II. These compounds were designed on the basis of previous findings from Ellman's group, who determined that large substituents were suitable for P1' position [69]. In comparison to Ellman's compounds, Nöteberg's had the nature of the peptidic inhibitor minimized using a single prime side amino acid residue bearing a biphenyl side chain. This yielded compounds which were highly selective for plasmepsins over cathepsin D, the most active of which $(\mathbf{8})$ is displayed in (Fig. 8).

In the same year, the same group also synthesized and screened compound libraries based on the general structure 9, and found inhibitors with $K_{\mathrm{i}}$ values in low nanomolar range that targeted the malaria proteases Plm I and Plm II, again with high selectivity versus cathepsin D (Fig. 9) [62]. This study allowed not only to find very active and selective inhibitors, like $\mathbf{1 0}$ (Fig. 9), as well as to demonstrate that 


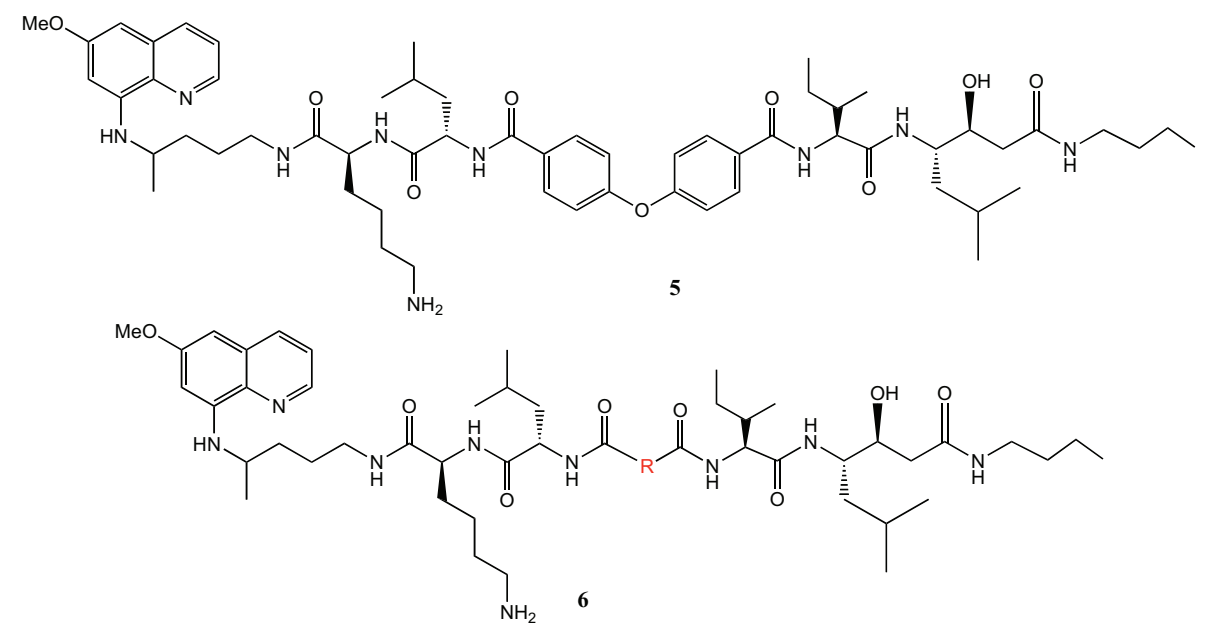

Fig. (6). General structure of statine-based inhibitors coupled with primaquine (6) designed by Bosisio and coworkers [64]. Compound 5 corresponds to the most active inhibitor of this series.

very diverse side chains in $\mathrm{P} 1$ ' and $\mathrm{P} 3$ positions are suitable for Plm I and II inhibition.<smiles>CCCCCO[C@@H](C(=O)NCc1ccccc1)[C@@H](O)CNC(=O)NCCN1CCCCC1</smiles>

Fig. (7). The most active Plm I and Plm II inhibitor, based on the statine-reversed core, designed by Samuelsson and co-workers [54]. $\mathrm{Bn}=$ Benzyl; Cbz=Benzyloxycarbonyl.

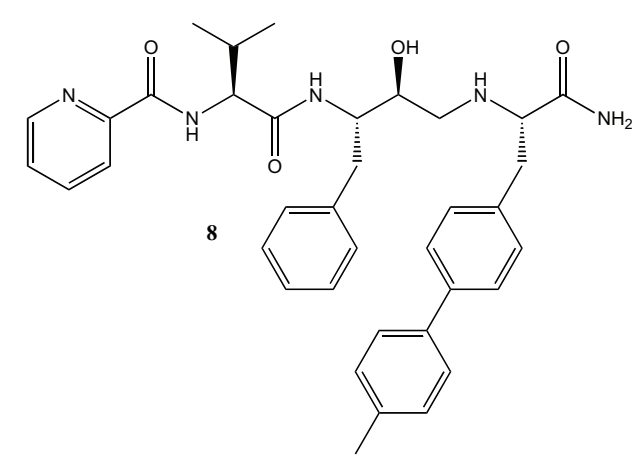

Fig. (8). The most active Plm I and Plm II inhibitor of the biphenyl series developed by Nöteberg and co-workers: $K_{\mathrm{i}}(\mathrm{Plm} \mathrm{I})=115 \mathrm{nM}$; $K_{\mathrm{i}}(\mathrm{Plm} \mathrm{II})=121 \mathrm{nM}[61]$.

Most of the reports on Plm II inhibitors describe non covalent interactions with the aspartyl proteases. However, there are a few examples of irreversible inhibitors in the literature [70-72]. Woster and co-workers [71] studied the synthesis and screening of Plm II inhibitors and found that three compounds produced irreversible inactivation of the enzyme with $\mathrm{IC}_{50}$ values in the low nanomolar range. They hypothesized that an (S)-hydroxyl substituent moiety bearing a latent electrophile should act as an irreversible inhibitor of Plm II. For instance, Asp214 or an adjacent basic amino acid could abstract an acidic proton from the inactive electrophile re- sulting in the generation of an $\alpha, \beta$-unsaturated system (11), ketenimine (12), or an allene (13 and 14) in the catalytic site (Fig. 10).<smiles>[R]C(=O)N[C@H](C(=O)N[C@@H](Cc1ccccc1)[C@@H](O)CN[C@@H](Cc1ccc([R])cc1)C(N)=O)C(C)C</smiles><smiles>CC(C)[C@H](NC(=O)C1CCCCC1)C(=O)N[C@@H](Cc1ccccc1)[C@H](O)CN[C@@H](Cc1ccc(-c2ccc3c(c2)OCO3)cc1)C(N)=O</smiles>

Fig. (9). Core structure 9 of the library of potential Plm I and Plm II inhibitors studied by Nöteberg's team. Compound $\mathbf{1 0}$ was the most active and selective inhibitor, with $K_{\mathrm{i}}(\mathrm{Plm} \mathrm{I})=12 \mathrm{nM} ; K_{\mathrm{i}}(\mathrm{Plm}$ II $)=110 \mathrm{nM}$; and $K_{\mathrm{i}}($ Cathepsin D $)=3300 \mathrm{nM}[62]$.

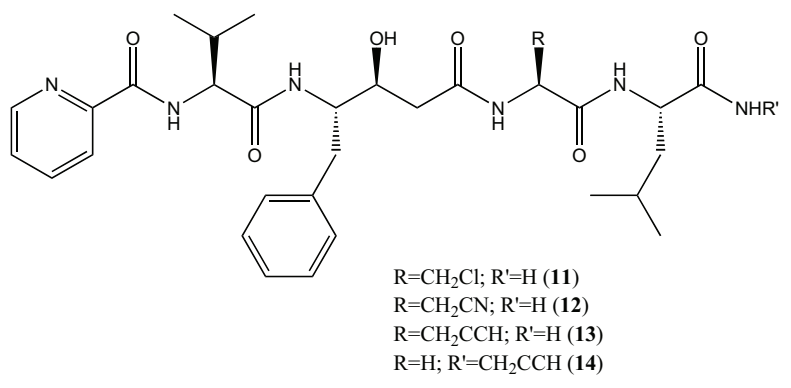

Fig. (10). Structures of irreversible Plm II studied by Woster's group [71]. 
Woster's group found compounds $\mathbf{1 1}, \mathbf{1 3}$, and $\mathbf{1 4}$ to be active in nanomolar range between 20-350 nM. Interestingly, compound 14 showed the greatest selectivity for Plm II over cathepsin D despite the fact that the latent electrophile was not adjacent to the $(S)$-hydroxyl moiety. Compound $\mathbf{1 1}$ was a poor inhibitor of the parasite activity in vitro in the blood stage, contrary to compounds $\mathbf{1 3}$ and $\mathbf{1 4}$ which displayed $\mathrm{IC}_{50}$ values of 7.7 and $9.2 \mu \mathrm{M}$, respectively, in the infected erythrocyte assay. Still, the mechanism through which compounds $\mathbf{1 1}, \mathbf{1 3}$, and $\mathbf{1 4}$ exert their activity against the enzyme is unknown. Thus, additional studies are required in order to explain the specific amino acid residues which participate in the covalent bond formation.

In general, the aforementioned peptidomimetic inhibitors exhibit low nanomolar activity in vitro against plasmepsins, however their in vitro activity against blood stage parasites usually drops significantly. In other words, effective inhibition of plasmepsins was found to correlate poorly with parasite killing in culture [73]. This frequent effect might be attributed either to compounds possessing unfavorable pharmacokinetic properties, e.g. poor cell permeability, or to the fact that not all four plasmepsins are inhibited equally well.

Although most Plm I and II inhibitors are peptidomimetic compounds that mimic the tetrahedral intermediate formed during the aspartyl protease catalysis, some nonpeptidic molecules have generally been more successful than the peptidomimetic inhibitors in demonstrating high activities in cell culture [74]. This may be the result of more appropriate structural profiles for membrane permeability. A number of nonpeptide plasmepsin inhibitors displaying low nanomolar range against parasite growth in vitro (Fig. 11) have been reported [75].

Via a high-throughput screening of the Roche compound library, substituted piperidines were identified and further developed as inhibitors of the aspartyl protease renin [76]. Subsequent structural optimization of the initial lead structure, found to inhibit Plm I and Plm II with an $\mathrm{IC}_{50}$ value of about $1 \mu \mathrm{M}$ for both variants, resulted in compounds, such as compound 15 (Fig. 11), exhibiting nanomolar activity in cellular assays [77].

Another study, reported by Boss and co-workers [78], of high-throughput screening of a commercial library using fluorescence resonance energy transfer (FRET) assays to measure the Plm II activity, identified low $\mu \mathrm{M}$ inhibitors such as type I and type II (Fig. 12) as promising compound classes. Further optimization of the compounds was able to increase the activity of type I and type II inhibitors by 250 fold and a factor of 60 , respectively. Such improvements led to compound 16 (Fig. 11) and 17 (Fig. 13), respectively [77, 78]. The binding modes of the 4-aminopiperidines (compound 16) were elucidated by X-ray crystallography (PDBcode: 2BJU) [79], which certainly will facilitate the subsequent structure-based drug design of this promising class of compounds.

For type II inhibitors, replacement of the $n$-pentyl chain by shorter ones, as well as the insertion of a heteroatom in the chain, leads to a decrease on the activity of the inhibitors against Plm II. Still, little is known about the consequences on the activity of type II inhibitors upon alterations of $\mathrm{R}^{3}$ and $\mathrm{R}^{4}$ substituents. Boss and co-workers [78] demonstrated that hydrophilicity and polarity in the bis-heteroaryl moiety could be added to improved activity against the parasite growth. Their studies also showed that the aryl-amide unit and the aryl-amine are beneficial for global activity. Compound 17, an aryl-amine derivative shown in (Fig. 13), was found to be one of the most promising inhibitors against Plm II and parasite growth of the series of compounds considered, having $\mathrm{IC}_{50}$ values of $374 \mathrm{nM}$ against Plm II and $273 \mathrm{nM}$ against the parasite development.

In addition, other non peptidic inhibitors of plasmepsins include the achiral oligoamines reported by Diederich and co-workers [80]. They developed an initial library of 11 compounds and tested them against six different aspartyl proteases. Several hits were identified and some of them were found to be also selective. They demonstrated that the sulfonamides acceptor groups are preferred over the carbonyl moiety because they allow additional degrees of freedom. Polymethylene links confer flexibility to the oligoamine derivatives, which requires a high degree of pre-organization from the molecules before binding to the protein. One of the most active inhibitors of this series against Plm II, compound 18 shown in (Fig. 14), exhibited $K_{\mathrm{i}}$ value of $7.0 \mu \mathrm{M}$.

Noteworthy, several of the peptidomimetic and nonpeptide plasmepsin inhibitors have been assessed against both chloroquine-resistant and chloroquine-sensitive strains of $P f$ with similar potencies against both strains, indicating no cross-resistance between chloroquine and plasmepsin inhibitors $[64,75]$.

\subsection{Cysteine Proteases (Falcipains)}

After aspartyl proteases carry out the first cleavage of the hemoglobin into two peptide chains, falcipains (FPs) come to<smiles>COc1cccc(C(=O)OCc2ccc([C@H]3CCNC[C@@H]3OCc3ccc4ccccc4c3O)cc2)c1</smiles><smiles>CCCCCc1ccc(C(=O)N(Cc2ccc(-c3cccnc3)cc2)C2CCN(Cc3ccc(O)cc3)CC2)cc1</smiles>

Fig. (11). Non-peptidic Plm II inhibitors with $P f \mathrm{IC}_{50}$ values of $50 \mathrm{nM}(\mathbf{1 5})$ and $252 \mathrm{nM}(\mathbf{1 6})[75,77]$. 
play their role to transform those peptides into smaller ones. FPs are papain-like cysteine proteases and the best characterized Cys proteases of the malaria parasite, in which a Cys catalyzes protein hydrolysis via nucleophilic attack to the carbonyl carbon of a susceptible bond (Fig. 15). Analysis of the $P f$ genome sequence suggested the existence of four FPs: FP1, FP2 (EC number: 3.4.22.B69), FP2', and FP3 [81].<smiles>[R]CC(C([R])=O)N1CCN([R])CC1</smiles>

Type I inhibitors<smiles>[R]CC([Se][Se]C([R])[R])C([R])=O</smiles>

Type II inhibitors
Fig. (12). General structure of type I and type tertiary amines as inhibitors of Plm II [78].<smiles>CCCCCc1ccc(C(=O)N(CCN(CCCC)CCCC)Cc2ccc(-c3cccnc3)cc2)cc1</smiles>

Fig. (13). Compound 17, one of the most active aryl-amine derivatives against Plm II and parasite development with $\mathrm{IC}_{50}$ values of $374 \mathrm{nM}$ and $273 \mathrm{nM}$, respectively [78].<smiles>O=S(=O)(c1ccccc1)N(CNCN(Cc1ccccc1)S(=O)(=O)c1ccccc1)Cc1ccccc1</smiles>

Fig. (14). Compound 18, one of the most active oligoamine derivatives against Plm II with $K_{\mathrm{i}}$ value of $7 \mu \mathrm{M}$, reported by Diederich and co-workers [80].

FP1 is distantly related to the other FPs in terms of sequence ( $<40 \%$ amino acid identity) and its exact physiological role has yet to be elucidated. Some studies suggested that FP1 could be important in oocyst production during parasite development in the mosquito midgut [82] and also could help in the invasion of the host cell by $P f$. However, disruption of the FP1 gene does not disturb the parasite growth in the blood stage of the malaria life cycle [83]. Furthermore, a study showed that FP1 knockout parasites developed normally in erythrocytes, suggesting that this protease alone is neither required for parasite invasion nor for intracellular development within erythrocytes [84]. FP2, FP2' and FP3 are closely related and appear to be the key hemoglobinases in the acidic FV. FP2 is the most studied and FP2' is thought to arise by gene duplication, presenting $93 \%$ a.a. similarity with FP2 [85].<smiles>[R]C(=O)NCCC[Se]</smiles>

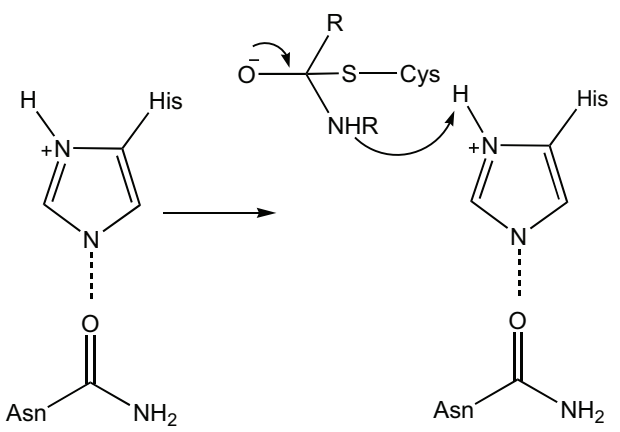

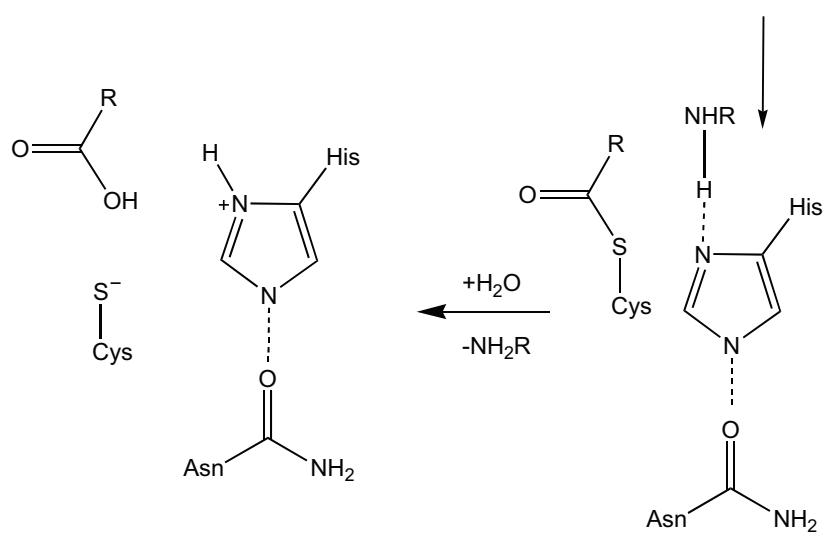

Fig. (15). Mechanism of peptide cleavage mediated by falcipains, Cys proteases of $P f$.

FP2 and FP3 are single polypeptide chains presenting a high similarity in sequence (68\% identity) and sharing similar sized prodomains. Their catalytic site has Cys and His residues (Fig. 16), whose side chains form a thiolate/imidazolium ion pair, and has also an Asn, responsible for correct orientation of the ion pair [81]. FP2 and FP3 contribute equally to hemoglobin degradation and both require reducing environment and acidic $\mathrm{pH}$ for optimal activity. Interestingly, the disruption of FP2 gene revealed that the loss of this enzyme alone is not sufficient to cause parasite lethality, thus suggesting the participation of additional cysteine proteases for parasite invasion and growth in human erythrocytes [86]. In contrast, the FP3 gene could not be disrupted, revealing that FP3 is essential to erythrocytic parasites and therefore indicating that efforts to develop cysteine protease inhibitors as antimalarial drugs should probably be focused on FP2 and FP3 [86]. The structural similarities of FP2 and FP3 can be a reason for these proteases performing similar functions in the FV. One difference between FP2 and FP3 is that FP3 showed to be far less active than FP2 against peptide substrates. However, FP3 is more active and stable at acid $\mathrm{pH}$ (as in the parasite's FV) than FP2 [87]. Also, it has been estimated that the concentration of FP2 in trophozoites is 1.8 times that of FP3. Still, FP3 processes globin two times faster than FP2 does [88]. The structures of FP2 and FP3 forming complexes with known inhibitors of other Cys proteases have been reported: the FP2 crystal structure was reported in a complex with inhibitor E64 19 (PDB code $=3$ BPF) $[83]$ and the crystal structure of FP3 in a complex with Leupeptin 20 (PDB code=3BPM) [83] (Fig. 16) and with a vinyl sulfone (PDB code $=3 \mathrm{BWK}$ ) [89]. Both FP2 
and FP3 showed to have a preference for substrates with a hydrophobic residue, especially leucine, at P2 position.

Although both FP2 and FP3 contribute almost equally to the digestion of hemoglobin, FP3 is usually less amenable to inhibition by peptidyl-based small molecules [83]; consequently, there is a variety of FP2 inhibitors in the literature [86]. In general, FP inhibitors can be classified in peptidylbased inhibitors (covalent irreversible and reversible inhibitors) $[83,90,91]$, including peptidomimetic compounds [92, 93], and nonpeptidic small inhibitors [94-96].

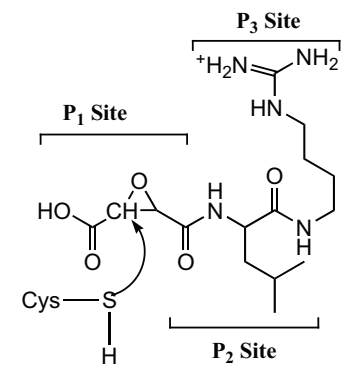

19

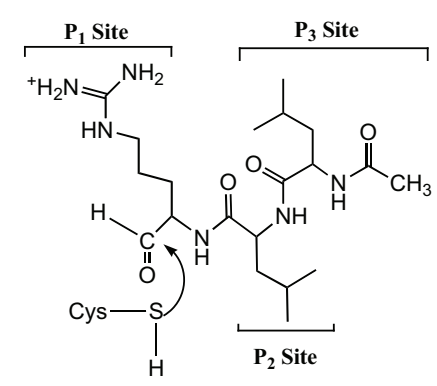

20
Fig. (16). Structures of known Cys protease inhibitors E64 (19) and Leupeptin (20).

\subsubsection{Peptidyl-Based Inhibitors}

\subsubsection{Irreversible Inhibitors}

Most of the falcipain inhibitors identified so far are peptidyl-based molecules [86]. Given that Cys proteases have their enzymatic roles dependent on a catalytic Cys residue, an electrophilic warhead is necessary to inhibit these proteases. Among such warheads, prone to bind in a irreversible way to FPs, like fluoromethyl ketones [97], epoxysuccinyl [98] or azirine [98] derivatives, the most used are Michael acceptors that irreversibly inactivate Cys proteases via alkylation of the side chain thiolate of the Cys residue (Fig. 17) [37]. These Cys protease inhibitors include an $\alpha, \beta-$ unsaturated conjugated system such as vinyl sulfone or $\alpha, \beta$ unsaturated carbonyls $[99,100]$.
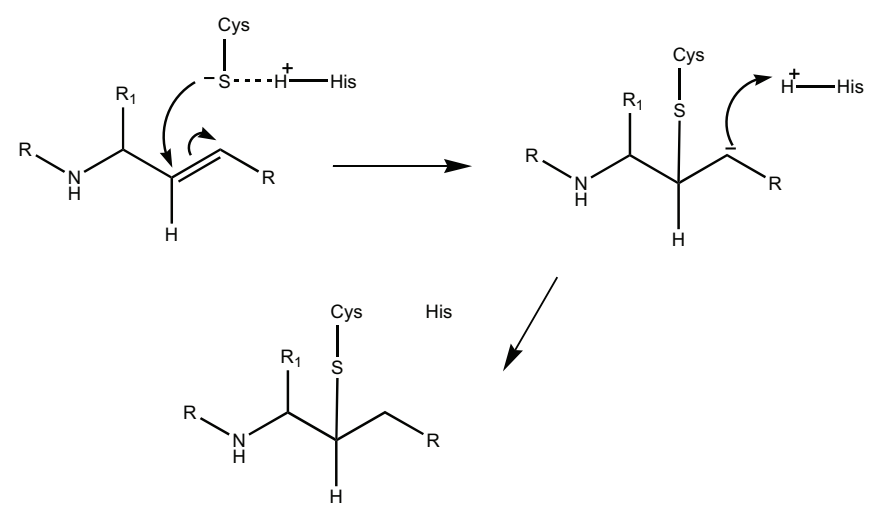

Fig. (17). Schematic view of irreversible alkylation of a Cys via Michael addition.

Since Rosenthal and co-workers [100] reported in 1996 that vinyl sulfone inhibitors of FP2 blocked the development of $P f$ in culture and presented antimalarial activity in vivo, there have been several efforts to synthesize Cys protease inhibitors. The best known attempt was done by the same research team in 2003 [101], when they reported the structure-activity relationships (SAR) for a series of peptidyl vinyl sulfones, vinyl sulfone esters, and vinyl sulfonamides as inhibitors of FP2 and FP3. In that study, they demonstrated that the SAR for the two proteases are similar and found multiple compounds to be potent inhibitors of both falcipains, especially amongst the vinyl sulfones (21, Fig. 18).

Studies of Rosenthal's group showed that the SAR of FP2 and FP3 are similar and several compounds are potent inhibitors of falcipains and parasite growth. Also, the SAR for the inhibition of the proteases differed notably for those of inhibition of parasite development. In the SAR regarding the proteases, Rosenthal's team found that inhibitors with the dipeptide core Leucine-homoPhenylalanine (Leu-hPhe) in P2-P1 provided potent inhibition for FP2, FP3 and for development of malaria parasites in vitro, and that potency was imparted by alterations of amino (P3)- and carboxy (P1')terminal substituents of vinyl sulfone. Still, substrates with Leu at P2 showed to be less active against FP3 than against FP2. Compounds with the core sequence Phe-hPhe exhibited modest FP2 inhibitory activity and changes at position P3 in these molecules had relatively low impact on activity. Compounds with the dipeptide sequence Phe- $O$-(phenyl)Ser had inhibitory activities with $\mathrm{IC}_{50}$ against FP2 from 56 to 290 $\mathrm{nM}$. The same group then tested 30 compounds with the core sequence Phe-hPhe, which differed at the P1' and P3 position. Vinyl sulfonamides and vinyl sulfones were seen to be less active against FP2 than the vinyl sulfonate esters. Still, inhibitory activity against parasite growth was higher for vinyl sulfones. Finally, these authors also found a pattern of activity against the parasite cultures, depending on the substitution in the aryl ring of the vinyl sulfonate esters: presence of the electron-donating methoxy group led to an increase of activity over the unsubstituted ring, whereas the last one showed to be more active than the one bearing an electron-withdrawing fluorine [101]. More recently, a computational 3D-QSAR study on these three vinyl sulfone, sulfonamide and sulfonate ester families has identified critical regions where any change in the steric, electrostatic, and hydrophobic fields of the molecules may affect the inhibitory activity [102]. For instance, bulky groups at $\mathrm{R}_{2}$ position (Fig. 18) tend to decrease biological activity while electropositive groups at $\mathrm{R}_{2}$ backbone, $\mathrm{R}_{1}$ side-chain and near the $\mathrm{SO}_{2}-\mathrm{R}_{1}$, group are preferred to improve FP2 inhibitory activity. Also, compounds that orient any hydrophobic part of $\mathrm{R}_{3}$ group towards Tyr78 and Leu84 would exhibit enhanced FP2 inhibitory activity. Additionally, they also postulated that the general rank order of FP2 inhibitory activity, sulfonate esters $>$ sulfonamide $>$ sulfones, observed when comparing compounds that only differ on $\mathrm{R}_{1}$ ' substituent could be related to the flexibility of this substituent.

Though peptidyl-based inhibitors like those above inhibit enzymatic activity of FPs at very low nanomolar range, their utility as therapeutic agents may be limited for their susceptibility to protease degradation and their poor absorption through cell membranes, so peptidomimetic scaffolds have been developed to bypass this problem [86]. A common strategy to avoid the therapeutic limitations of peptide-based 


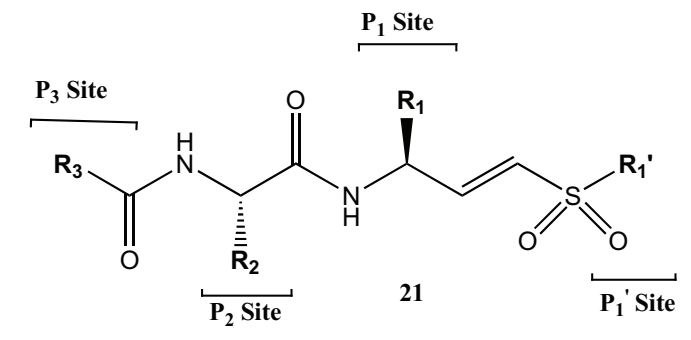

$$
\mathbf{R}_{1} \text { : homoPhe, O-(phenyl)Ser }
$$

Fig. (18). Structure of vinyl sulfone inhibitors of FP2/3 with nanomolar activity against intra-erythrocytic $P f$ parasites [101].

inhibitors is to lock a defined conformation of the peptide into a rigid scaffold. There are several examples of peptidomimetic inhibitors of FP2 reported in the literature [92, 93, 103-106]. O’Neill and co-workers designed and synthesized novel 2-pyridone peptidomimetic FP2/3 inhibitors with chemical structures shown in (Fig. 19) [107]. All of these molecules displayed antimalarial activity in the micromolar range, being $\mathbf{2 2}$ the most active inhibitor of the series with an $\mathrm{IC}_{50}(3 \mathrm{D} 7 \mathrm{Pf})$ value of $5.7 \mu \mathrm{M}$, followed by the $\alpha, \beta$ unsaturated methyl ester $\mathbf{2 3}$ with an $\mathrm{IC}_{50}$ (3D7 Pf) value of $27.9 \mu \mathrm{M}$. Compound $\mathbf{2 4}$ was less active than their counterparts bearing the unnatural segment of hPhe residue. However, only $\mathbf{2 4}$ expressed activity against FP2/3, whereas the low solubility of $\mathbf{2 2}$ prevented its evaluation as a potential FP inhibitor.

$$
\begin{aligned}
& \mathrm{R}=\mathrm{C}_{2} \mathrm{H}_{4} \mathrm{Ph} ; \mathrm{R}^{\prime}=\mathrm{SO}_{2} \mathrm{Ph} \\
& \mathrm{R}=\mathrm{C}_{2} \mathrm{H}_{4} \mathrm{Ph} ; \mathrm{R}^{\prime}=\mathrm{COOMe} \mathrm{(23)}_{\mathrm{R}} \\
& \mathrm{R}=\mathrm{CH}_{2} \mathrm{Ph} ; \mathrm{ROO}^{\prime}=\mathrm{SO}_{2} \mathrm{Ph}
\end{aligned}
$$

Fig. (19). FP2/3 peptidomimetic inhibitors studied by O' Neill and co-workers [107]. Cbz=Benzyloxycarbonyl.

Other peptidomimetics bearing Michael-acceptor moieties for irreversible FP inhibition have been explored as antimalarials. For instance, Moreira and co-workers have developed vinyl sultams [108], aza vinyl sulfones [109], squaric acid [110] and 3-methylene substituted indolinone derivatives [111]; only some of the latter compounds were able to inhibit $P f$ parasites in vitro at $\mathrm{IC}_{50}$ as low as $140 \mathrm{nM}$, the remaining presenting $\mathrm{IC}_{50}$ values in the micromolar range. In general, none of these compounds was able to exhibit potent FP inhibition activity.

Peptidomimetic nitriles have also been reported in the literature as potential FP inhibitors. Nitriles are known to inhibit cysteine proteases by the formation of a covalent thioimidate adduct resulting from the nucleophilic attack of the active site Cys residue [112]. Using a rational structurebased molecular modeling focusing on optimal occupancy of the main apolar FP2 pockets to obtain potent and particularly selective inhibitors, Diederich and co-workers [103] were able to design nitrile inhibitors of FP2 action, and showed that the ideal occupation of the selectivity-determining S2 pocket and the balanced electrophilicity of the nitrile group seem to be essential to achieve activity and selectivity. The 3D modeling studies specifically revealed that 1aminocyclohexanecarboxylic acid should be the central core of the nitrile derivative to address the active site of FP2. The cyclohexyl motif should orientate the other substituents in the molecules to promote their interactions with the S2 and S3 pockets. They synthesized the nitriles derivatives and assessed their biological activity against FP2. Accordingly, the $\mathrm{S} 2$ pocket is accessible for different substituents of 5- or 6-membered aromatic systems such as pyridin-3-yl, 4methoxyphenyl, 2-methoxyphenyl, 3,4-dimethoxyphenyl, furan-2-yl, and thiophen-2-yl. Also, loss of activity was observed when the 2-aminoisobutyric acid substituted the 1aminocyclohexanecarboxylic acid as a center core. Most of the derivatives exhibited high selectivity against FPs versus cathepsin B and L, as well as against the serine protease $\alpha$ chymotrypsin, making them interesting targets for further optimization studies toward the discovery of new potent antimalarials. Compound 25, one of the most active inhibitors of the series against FP2 action is displayed in (Fig. 20).<smiles>N#CCNC(=O)C1(NC(=O)OCc2ccccc2)CCCCC1</smiles>

Fig. (20). Compound 25, one of the best inhibitors designed by Diederich and co-workers [103] with a $K_{\mathrm{i}}$ value against FP2 of 1.2 $\mu \mathrm{M}$.

Most recent examples of peptidyl-based structures as potential FP inhibitors include those reported by Gomes and co-workers [105]. They designed and synthesized a series of cinnamic acid/4-aminoquinoline derivatives as potential inhibitors of falcipain action and found the unsubstituted cinnamic acid derivative 26 (Fig. 21) to inhibit not only FP2 action but also the parasite growth in vitro in the micromolar range. The retro enantio dipeptide used to link the 4aminoquinoline and the respective cinnamic acid was demonstrated to provide antimalarial activity. Interestingly, using the natural counterparts of the amino acids in the linker 
dipeptide was detrimental to compound inhibitory activity against FP2 and also resulted in a decrease in the antiplasmodial activity. Furthermore, some of the compounds from the series exhibited activity against hemozoin biocrystallization and FP2 making them good leads toward the development of potential dual action antimalarials.<smiles>CC(C)C[C@H](NC(=O)C#Cc1ccccc1)C(=O)N[C@@H](CCc1ccccc1)C(=O)Nc1ccnc2cc(Cl)ccc12</smiles>

Fig. (21). The most active FP2 inhibitor among the new series proposed by Gomes and co-workers [105].

All the above examples demonstrate that, with the exception of vinyl sulfones unveiled by Rosenthal's group, compounds able to irreversibly inhibit FP and display nanomolar activities against $P f$ have been hard to find. Hence, several groups have developed novel structures where the vinyl sulfone moiety is conserved in an attempt to ensure FP irreversible inhibition. An example of such strategy is that of Zappalà's team $[92,93]$. These authors synthesized a series of Cys protease inhibitors based on the 1,4-benzodiazepine scaffold, which is known to act as a good mimetic of $\beta$-turns [113], the structural motif postulated as the biological active form of the $D$-Ser-Gly peptide [114]. Furthermore, benzodiazepines are also known to enhance oral bioavailabilitity and also to increase stability toward premature proteolytic degradation by enzymes. In this connection, Zappalà and coworkers [93] focused their attention on the synthesis of two different series both including a vinyl sulfone in the P1'site (Fig. 22). One series contained hPhe in $\mathrm{P} 1$, a residue known to increase the inhibitors potency against FPs, and the second series included Gly in P1 to assess the relevance of the amino acid side chain for enzyme recognition. All of the vinyl sulfone inhibitors displayed activity against the parasite higher than $9.1 \mu \mathrm{M}$. As expected, compounds with hPhe residue in $\mathrm{P} 1$ site were generally better inhibitors of parasite development than compounds containing a Gly. Compounds 27a and 27b (Fig. 22) presented good FP2 inhibitory activities and also the highest antiplasmodial activities of the corresponding series [93]. In addition, the compounds were tested against cathepsin B and L and found to be weak inhibitors of these two enzymes, which can be considered a promising result regarding their selectivity toward parasite versus host Cys proteases. Thus, these compounds can be considered as leads for the development of new antimalarials.

Following, Zappalà's group reported a series of compounds synthesized based on the same 1,4-benzodiazepine scaffold with the aim of improving the pharmacological properties of this type of irreversible inhibitors [92]. In that work, they described a highly potent and selective derivative with a vinyl ester warhead $\mathbf{2 8}$ (Fig. 23), which exhibited the highest potency with an activity two times higher than that of the standard E-64 $\left(k_{\text {second }} 1586000 \mathrm{M}^{-1} \mathrm{~min}^{-1}\right)$ and the highest enzymatic affinity $\left(K_{\mathrm{i}}=17 \mathrm{nM}\right)$ among the series. Although 28 displayed a $K_{\mathrm{i}} 17 \mathrm{nM}$, it did not result as active in vivo, supposedly, due to the difficulty for the derivative to cross the biological membranes of the parasites and reach FP2.

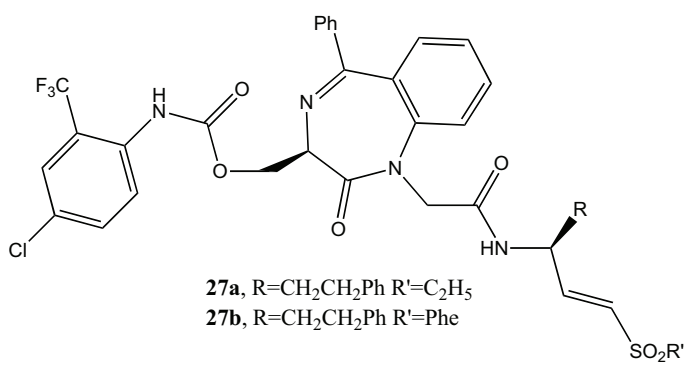

Fig. (22). FP2 inhibitors, designed by Zappalà's team, combining a benzodiazepine core and a vinyl sulfone warhead [93].

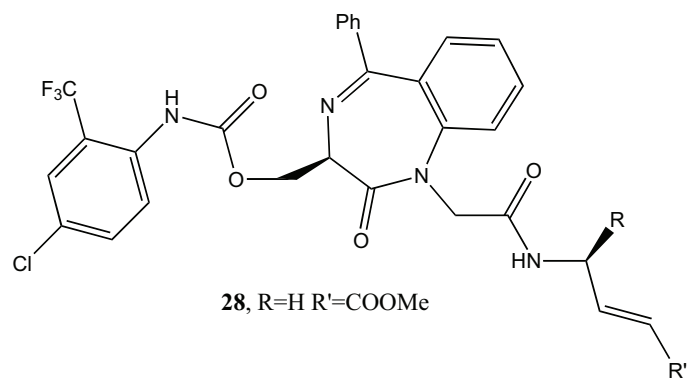

Fig. (23). Most potent compound of the series 28 reported by Zappalà and co-workers [92].

The unmatched relevance of the dipeptidyl vinyl sulfone warhead for FP inhibition has been also recognized in research works where this moiety has been combined with other antimalarial scaffolds, e.g., artemisinin, to produce multi-target antimalarial molecules 29 (Fig. 24) [115].

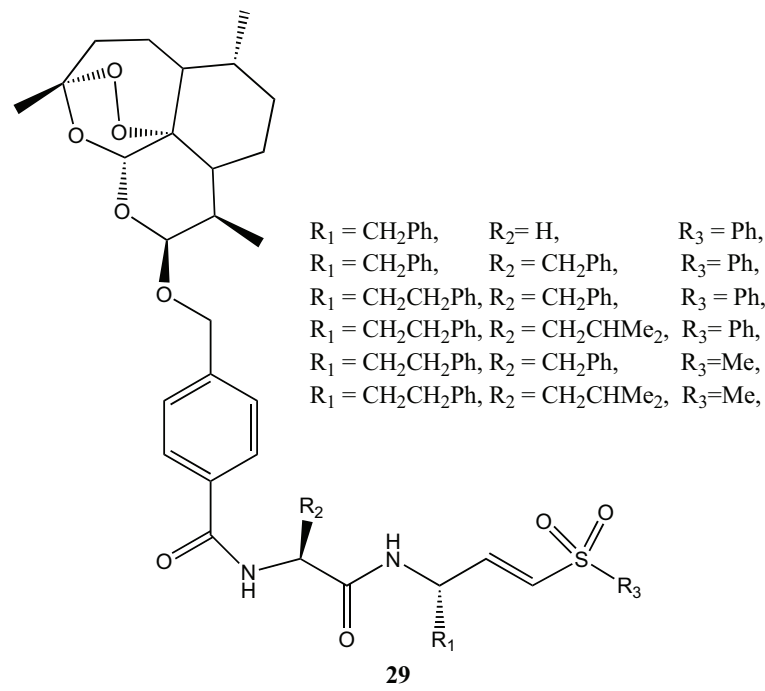

Fig. (24). Artemisinin-dipeptidyl vinyl sulfone hybrids 29 developed by Moreira's team [115].

\subsubsection{Reversible Inhibitors}

An example of reversible inhibitors was reported by Zappalà's team [104]. These authors synthesized a series of 
Cys protease inhibitors based on the 1,4-benzodiazepine scaffold linked to a $C$-terminal aspartyl aldehyde building block that would inhibit the enzyme by forming a covalent reversible bond. All of the designed benzodiazepine derivatives presented activity against $\mathrm{FP} 2$ with $\mathrm{IC}_{50}$ values between 8 and $26 \mu \mathrm{M}$. The derivative of compound $\mathbf{3 0}$ obtained by introducing a phenyl group at $\mathrm{R}$ position (Fig. 25) was the least potent inhibitor of the series with an $\mathrm{IC}_{50}$ of $21.54 \mu \mathrm{M}$. The introduction of an electro-withdrawing or electrodonating group to the para position of the phenyl ring in the general structure 30 (Fig. 25) increased the activity against the enzyme. An enhancement of the activity against FP2 was also observed by the insertion of a methyl or a trifluoromethyl group to the $p$-chlorophenyl ring (c.f. compound $\mathbf{3 1}$ in Fig. 25). To evaluate the selectivity of the compounds, the derivatives were tested against a panel of active recombinant human caspases (i.e., caspases 1-9) and the molecules displayed inhibitory activity up to $50 \mu \mathrm{M}$.

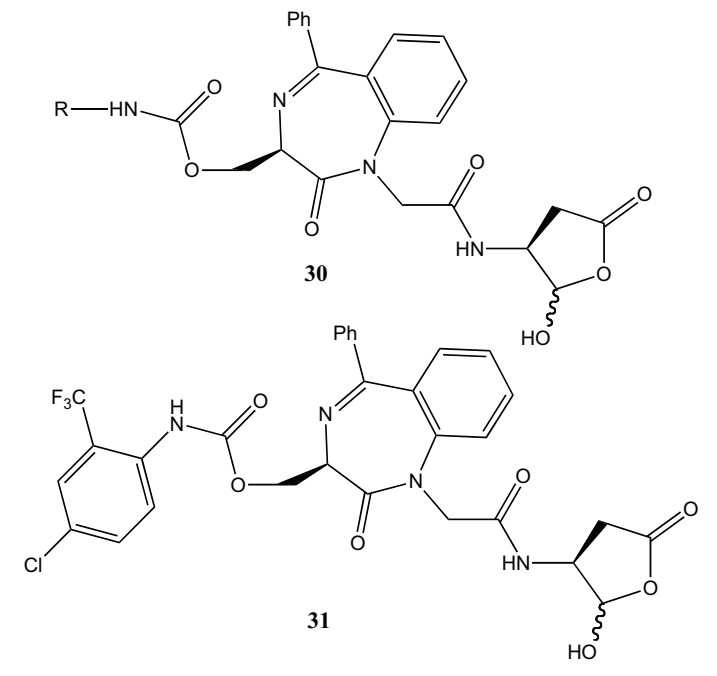

Fig. (25). General structure 30 for the design of benzodiazepine inhibitors with a P1-aspartyl aldehyde moiety and compound 31, one of the best inhibitors of the series [104].

Other examples of reversible inhibitors include the ones reported by O'Neill and co-workers [90]. They studied examples of FP2 and FP3 inhibitors that do not have an $\alpha, \beta$ unsaturated system included in the structure and inhibit FPs in a reversible manner. They were able to synthesize two molecules, namely, compounds 32 and 33 in (Fig. 26), bearing an aldehyde moiety which displayed activity against FP2 and FP3 in the low nanomolar range, and also expressed activity versus the $3 \mathrm{D} 7$ strain of $P f$. Both molecules contained residues Leu and homoPhe, the key amino acids previously identified by Rosenthal and co-workers [90], and were found to possess a good enzyme fit according to docking studies.

Other peptidyl reversible inhibitors of falcipains include peptidyl aldehyde and $\alpha$-ketoamide derivatives developed by Rosenthal and co-workers [91]. They evaluated FP2 inhibition and antimalarial activity of the series and found most of the compounds to inhibit FP2 activity in nanomolar range. Due to the high sequence similarities between FP2 and FP3, they decided to test the compounds also against FP3 and activity against both falcipains resulted to be similar, suggesting that a single small specific protease inhibitor could be enough to inhibit both falcipains and consequently, inhibit hemoglobin degradation leading to parasite death. As seen previously in other works, the compounds which displayed higher activity against the protease had a Leu in P2 site contrary to those who had a Phe in P2. Inhibition of FP2 was always accompanied by swollen and darkly stained parasitic $\mathrm{FV}$, an experimental finding that agrees with blocking of hemoglobin degradation [116]. Since new ideal antimalarials should be active against all $P f$ strains, Rosenthal and coworkers decided to test the three best inhibitors of the series against other five $P f$ strains. They found the three compounds to inhibit more or less equally each strain and that there was no evidence that the activity against multidrugresistant strains differed from the activity against broadly sensitive strains. The morpholino-carbonyl-leucinehomophe-nylalanine aldehyde 34 (Fig. 27) exhibited excellent activity against FP2 and parasite development. Rosenthal's team assessed the activity of the $P$. vinckei-mice and the compound $\mathbf{3 4}$ showed antimalarial activity when it was administered intraperitonially but this activity was fairly low. They inferred that compound $\mathbf{3 4}$ activity could be mainly due to the short life of the compound. Thus, due to the poor pharmacokinetic of the compound to provide consistent levels in blood and to improve drug delivery, mice were dosed by a subcutaneous infusion pump continuously. However, the antimalarial activity continued to be modest and the mice eventually died by the infection.<smiles>[R]N[C@@H](CC(C)C)C(=O)N[C@H](C=O)CCc1ccccc1</smiles>

Fig. (26). FP2/3 reversible inhibitors developed by O'Neill and coworkers [90]. $\mathrm{Mu}=$ Morpholine urea; $\mathrm{Cbz}=$ Benzyloxycarbonyl.<smiles>CC(C)C[C@H](CC(=O)N1CCOCC1)C(=O)N[C@@H](C=O)CCc1ccccc1</smiles>

Fig. (27). Most active peptidyl reversible inhibitor 34 developed by Rosenthal and co-workers [91]. 


\subsubsection{Non-Peptidic Inhibitors}

In an effort to develop non-peptidic FP2 inhibitors, Zappalà's group reported a series of 1-aryl-6,7-disubstituted-2Hisoquinolin-3-ones which were synthesized and tested against FP2, as well as against cultured $P f$ strain FCBR parasites. Most compounds presented activity against the enzyme though there were not selective. The most potent compound of the series 35 (Fig. 28) displayed a $K_{\mathrm{i}}=2.3 \mu \mathrm{M}$ against FP2 emphasizing the importance of hydrophobic and bulky groups at position 6 and 7 of the isoquinoline scaffold [117]. Further work is required in order to improve the selectivity of these compounds because they resulted to be slightly more active against human cathepsins than FP2.<smiles>COc1ccc(-c2c3cc(OCc4ccccc4)c(OCc4ccccc4)cc3cc(=O)n2N)cc1</smiles>

Fig. (28). Most potent compound 35 of the series reported by Zappalà and co-workers [117].

Several other non-peptidic small inhibitors of FPs have been found [118-121], some of them through computerbased drug design and virtual screening studies, for instance, compounds 36-39 (Fig. 29) [94-96, 120]. Recently, Avery and co-workers [120] identified a total of 28 non-peptidic low micromolar inhibitors of FP2 and FP3 and elaborated SAR for each series. Some of the complex trends in the SAR could be explained by the energetical changes associated with the displacement of water molecules upon ligand binding, and other could be related with poor chemical reactivity of the reactive centers of these compounds. The motivation to use water energetical changes was due to the fact that the SAR could not be explained by none of the following descriptors: hydrogen bonds, van der Waals, and electrostatics interactions, or by ligand strain, or even by using traditional computational approaches such as molecular mechanics/generalized Born surface area (MM-GBSA), docking scores, and molecular mechanics interaction energies. Some of the molecules identified in this study also inhibited parasite growth in culture.

Some hybrid drugs, capable of targeting two processes in the malaria life cycle where one of the targets is FP2 inhibition, can fall into the category of non-peptidic small inhibitors $[122,123]$. For instance, in 2010, Chibale's group identified chalcone-chloroquine hybrid $\mathbf{4 0}$ as a promising antimalarial (Fig. 30) [122, 123]. Compound 40 and related hybrid structures were synthesized and showed to be active against $P f$. The molecules were tested as inhibitors of both FP and hemozoin formation, and some of them were found to be active in the micromolar range against FP. However, compound 40 and related structures did not show correlation between FP inhibition and parasite growth in culture. Still, there was consistent correlation between in vitro antimalarial potency and inhibition of hemozoin formation, suggesting that this could be the primary mechanism of their antimalarial activity.<smiles>O=C(O)c1ccccc1N/N=C/c1ccc(/C=N/Nc2ccccc2C(=O)O)cc1</smiles><smiles>O=S(=O)(NCc1ccco1)c1ccc2c(c1)Cc1cc(S(=O)(=O)NCc3ccco3)ccc1-2</smiles><smiles>C=CCn1c(SCC(=O)Nc2sc3c(c2C(N)=O)CCC3)nc2scc(-c3ccccc3)c2c1=O</smiles><smiles>Cc1ccc(Sc2ccc(NC(=O)Cn3nc(C(=O)O)c4ccccc4c3=O)cc2)c(C)c1</smiles>

Fig. (29). Non-peptidic FP inhibitors developed by Avery and coworkers [120].<smiles>COc1ccc(C(=O)/C=C/c2ccc(OCc3cn(-c4ccnc5cc(Cl)ccc45)nn3)c(OC)c2)c(OC)c1</smiles>

Fig. (30). Hybrid drug 40 designed to include FP inhibition $(\alpha, \beta$ unsaturated system as Michael acceptor) in its mode of antimalarial action $[122,123]$.

Other non-peptidic inhibitors include structural analogs of triazole (Fig. 31) and benzothiazole (Fig. 32) cores showing moderate inhibition of falcipains, reported by Avery and co-workers [124]. In the triazole series, in an effort to optimize the activity of compound $\mathbf{4 1}$ against FP2, only few triazoles with general structure $\mathbf{4 2}$ were found to display activity against FP2 but none was more active than the parent com- 
pound. The low activity of these derivatives might be ascribed to the unsuitable or shorter hydrophobic $\mathrm{R}$ groups used for this family as compared to the parent compound $\mathbf{4 1}$ that had an $\mathrm{IC}_{50}$ value of $2.2 \mu \mathrm{M}$. Indeed, molecules with bulkier $\mathrm{R}$ groups were the ones exhibiting modest activity against FP2.
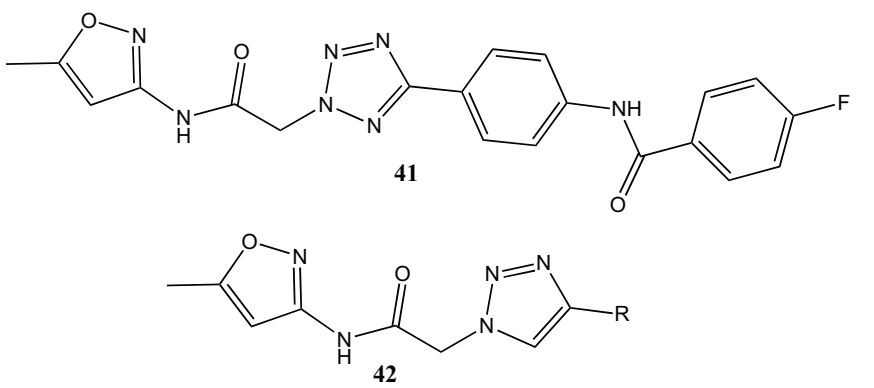

Fig. (31). General structure used to design triazoles by Avery's team [124].<smiles>CC(C)[C@H](N)C(=O)Nc1ccc2nc(SCC(=O)c3ccc4ccccc4c3)sc2c1</smiles>

Fig. (32). Benzothiazole based inhibitors as Plm II designed by Avery and co-workers [124].

In the benzothiazole series, compounds 43 and 44 were predicted by docking studies to interact with the polar residues of the S2 pockets of FP2 and FP3; these compounds inhibited both FP2 ( $\mathrm{IC}_{50}$ between 12.22-12.75 $\left.\mu \mathrm{M}\right)$ and FP3 ( $\mathrm{IC}_{50}$ between 13.77 and $14.94 \mu \mathrm{M}$ ), but also displayed activity against homologous mammalian cysteine proteases lacking polar residues, suggesting their low selectivity. Only compounds $\mathbf{4 4}$ and $\mathbf{4 5}$ inhibited the growth of W2 strain of $P f$, with $\mathrm{IC}_{50}$ values of $2.08 \mu \mathrm{M}$ and $4.65 \mu \mathrm{M}$, respectively.
Other non-peptidic FP inhibitors include heteroarylnitriles. For instance, Fiandor and co-workers [118] explored the pyrimidinenitrile scaffold for FP inhibition: optimization studies led to the discovery of 2-cyano-5-chloropyrimidines and 2-cyano-5-bromopyrimidines as promising inhibitors of the enzymes. Although some compounds inhibited falcipains in the subnanomolar and low nanomolar ranges, they only inhibited parasite growth in the micromolar range. However, introduction of a protonable amine resulting in analogs such as compound 46 (Fig. 33) led to an increase in antiplasmodial activity.<smiles>CC(C)CN(NC(=O)c1cccc(-c2ccc(N3CCN(C)CC3)cc2)c1)c1nc(C#N)ncc1Br</smiles>

Fig. (33). One of the best 2-cyano-5-bromopyrimidines, 46, developed by Fiandor's team: FP2 $\mathrm{IC}_{50}=0.5 \mathrm{nM}, \mathrm{FP} 3 \mathrm{IC}_{50}=3 \mathrm{nM}$ and $P f$ W2 $\mathrm{IC}_{50}=1 \mathrm{nM}[118]$.

Organometallic reversible FP inhibitors have also been proposed, namely, a series of gold derivatives reported by Messori and co-workers [125]. They found gold complexes capable of pronounced and reversible inhibition of FP2 in the micromolar range. Still, they were unable to establish a correlation between enzyme inhibition and antiplasmodial activity. Compound 47 (Fig. 34) displayed the lowest $K_{\mathrm{i}}(1.4 \mu \mathrm{M})$ of the series with an $\mathrm{IC}_{50}$ of $5.11 \mu \mathrm{M}$ against parasite growth.

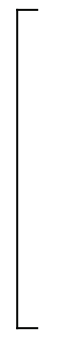<smiles></smiles>

$\left[\mathrm{PF}_{6}\right]$

47

Fig. (34). Gold derivative 47, with micromolar activity against parasite development [125].

More recently, Gomes and co-workers [105] developed non-peptidic inhibitors of FP2 including a cinnamoyl moiety. They synthesized a series of cinnamic acid/4-amino quinolines conjugates 48 (Fig. 35) with FP2 inhibitory activity in the micromolar range. By analyzing the binding modes of 48 docked to FP2, those authors observed that most of the compounds present the cinnamoyl group at the S2 cavity and having the vinyl group relatively close to the active residue of the cysteine protease. However, none of these inhibitors displayed antiplasmodial activity, probably due to low permeation into the infected red blood cell or into the parasitophorous vacuole inside it.

The combination of the inhibitory activity results regarding all falcipain inhibitors reported so far with the recent availability of crystal structures of both FP2 and FP3, will 
strongly help and support all the medicinal chemists currently involved in the discovery of potent falcipain inhibitors as promising molecules to combat malaria disease.<smiles>O=C(/C=C/c1cccc([N+](=O)[O-])c1)Nc1ccnc2cc(Cl)ccc12</smiles>

Fig. (35). Best inhibitor of the cinnamic acid derivatives reported by Gomes' team [105].

\subsection{Falcilysin}

The zinc metalloprotease falcilysin (FLN) is another protease that participates in the hemoglobin degradation process, specifically, in the hydrolysis of short globin peptides produced by FP-mediated proteolysis of globin [75, 126]. FLN is highly active at acidic $\mathrm{pH}$, which is consistent with its role in the $\mathrm{FV}$, but it is also active at neutral $\mathrm{pH}$, although with a different substrate specificity. At neutral and acidic $\mathrm{pH}$ this protease prefers to cleave sites in which P1' residues are bulky hydrophobic amino acids and has strong preference for methionine at P3'; however, in what concerns P2' residues, FLN favors hydrophobic residues at $\mathrm{pH}$ 5.2, whereas at $\mathrm{pH} 7.2$ it has stronger preference for Arg. Finally, at P4' and P5', FLN prefers acidic residues at acidic $\mathrm{pH}$ but is less selective at neutral $\mathrm{pH}$. Studies by Goldberg and coworkers [127] revealed that FLN is not only present in the FV but also in association with vesicular structures elsewhere in the parasitophorous vacuole, suggesting an expanded role for this protease in $P f$ biology. Despite some chelators, such as 1,10-phenanthroline [128] presented some activity toward this protease, no specific inhibitor was found so far [127-129].

\subsection{Dipeptidyl Amino Peptidase 1}

Once FLN converts short globin polypeptides into oligopeptides consisting of 5-10 amino acids, dipeptidyl amino peptidase 1 (DPAP1), a lysosomal exopeptidase, sequentially cleaves oligopeptide substrates from their $N$ terminus into dipeptides $[87,130]$. Attempts to disrupt the DPAP1 gene have been unsuccessful, which suggests that the enzyme makes an important contribution to hemoglobin catabolism during the intraerythrocytic cycle [131]. While DPAP1 is one of the three related DPAP enzymes encoded in the parasite genome, current evidence suggests that only DPAP1 resides in the food vacuole [130]. DPAP1 is also potentially a good drug target because the closest human homologue is cathepsin $\mathrm{C}$, a protease that is not essential in mammals $[130,132,133]$. DPAP1 differs from other endopeptidases in that they recognize the $\mathrm{N}$-terminal free amine of substrate proteins and cleave N-terminal dipeptides [134]. Structurally, its active site is relatively small compared to that of other endopeptidases and its substrate specificity is mainly dictated by the N-terminal residue P2 [134]. This smaller active site is more amenable to binding of bioactive mole- cules with low molecular weight and should be more suitable for computational docking and in-silico design of inhibitors.

Although DPAP1 is a fairly new target, some inhibitors of this protease have been already developed: Bogyo and coworkers [134] screened several non-peptidic scaffolds from a large library of small compounds that was initially designed to target cysteine cathepsins in mammals, and found stable covalent DPAP1 inhibitors 49 (Fig. 36) which kill Pf at low nanomolar concentrations.

Bogyo findings demonstrated that inhibition of DPAP1 by small compounds results in an immature trophozoite and, consequently, parasite death. This strongly suggests that development of DPAP1 inhibitors may be a key strategy toward malaria chemotherapy.<smiles>CCCCC(C(=O)COc1c(F)c(F)cc(F)c1F)n1cc([C@@](C)(N)C2CCCC2)nn1</smiles>

Fig. (36). Best DPAP1 inhibitor found by Bogyo's team [134].

\subsection{Exoaminopeptidases}

Pf contains nine exoaminopeptidases [135], four of which are methionine aminopeptidases (MetAPs). MetAPs catalyze the removal of $N$-terminal methionine during protein synthesis $[129,136]$ and their inhibition can impair $P f$ growth in culture $[24,129,137,138]$. The remaning five $P f$ exoaminopeptidases include an aspartic aminopeptidase, a prolyl aminopeptidase, a post-prolyl aminopeptidase, a leucine aminopeptidase, and an alanine aminopeptidase. These five aminopeptidases are considered to be potential targets for inhibition of hemoglobin degradation. Neutral alanine and leucine metallo-aminopeptidases [139], involved in the generation of free amino acids from the previously generated dipeptides, are the pivotal $P f$ exoaminopeptidases. Bestatin 50 (Fig. 37) has been found to inhibit both the activity of these enzymes and malaria parasite growth in vitro [36].<smiles>CC(C)C[C@H](NC(=O)[C@@H](O)[C@H](N)Cc1ccccc1)C(=O)O</smiles>

Fig. (37). Bestatin 50, a reported inhibitor of $P f$ Leu and Ala aminopeptidases [36].

\subsubsection{M1 Alanine Aminopeptidase}

PfA-M1 (EC number: 3.4.11.2) is a plasmodial zinc aminopeptidase that belongs to the M1-family which displays its activity at $\mathrm{pH} 7.4$ and has a broad substrate spectrum $[140,141]$. PfA-M1 is found in both trophozoites and 
schizonts, being involved in hemoglobin degradation and erythrocyte reinvasion [142]. Therefore, design and synthesis of potential inhibitors of the PfA-M1 activity can lead to the discovery of new antimalarials [141, 143, 144]. For example, Deprez-Poulain's group first identified three non peptidic and non-selective inhibitors of this protease, and further optimized their results, and found the desired specificity against mammalian neutral aminopeptidases (APN), the host M1 family prototype [141]. The compounds were based on malonic hydroxamic template $\mathbf{5 1}$ (Fig. 38) and the influence of the malonic substituents on the activity against PfA-M1 was analyzed: compounds bearing a benzyl or a $m$-phenozybenzyl group in R1 presented higher activity compared to those with an isobutyl substituent in that position. Binding of hydroxamate to the $\mathrm{Zn}^{2+}$ is expected to be the main anchoring point of the potential inhibitor. Therefore, substituents on R1 position should discriminate those molecules which will bind to the enzyme from those which will not. Compounds bearing a benzyl amine in R2 position, when presenting a fluorine atom in the para position or a methyl group on the ortho position, expressed strong increase on activity. To remove the chiral carbon, the same authors synthesized unsaturated analogues of 51, and found that a Z-configuration $\mathbf{5 2}$ led to increased activity, whereas an $E$-configuration had the opposite effect. Additionally, they found that cyclization of $\mathbf{5 2}$ to produce $\mathbf{5 3}$ was detrimental for enzyme inhibitory activity.<smiles>[R]C(=O)C([R])C(=O)NO</smiles>

51<smiles>O=C(NCc1ccc(F)cc1)c1cc2ccccc2n(O)c1=O</smiles>

53

Fig. (38). $P f A M-1$ inhibitors developed by Deprez-Poulain's group [141].

In addition, Deprez-Poulain's group has also developed quinoline inhibitors of PfA-M1 [145]. They discovered that the presence of a $\mathrm{Zn}$-chelating group is essential for the activity. They also found that the hydroxamate group is more efficient than a carboxylic acid group. The three PfA-M1 inhibitors are also inhibitors of the parasite growth and the quinoline moiety allows these compounds to also inhibit heme biocrystallization. The best inhibitor 54 (Fig. 39) of the synthesized compounds exhibited $\mathrm{IC}_{50}$ values of $0.854 \mu \mathrm{M}$ and $0.317 \mu \mathrm{M}$ against PfA-M1 or parasite growth, respectively.
Recently the X-ray structures of PfA-M1 in the apo form, in complex with bestatin (50, Fig. 37), and with a phosphinebased inhibitor, hPheP( $\left(\mathrm{CH}_{2}\right) \mathrm{Phe}(\mathbf{5 5}$, Fig. 40), originally designed for the cytosol leucine aminopeptidase [146], were determined by Dalton and co-workers (PDB codes: 3EBG, $3 \mathrm{EBH}, 3 \mathrm{EBI})$ [143]. The availability of these crystal structures will trigger the explanation of different affinities presented by different inhibitors allowing the early phase of inhibitors optimization.

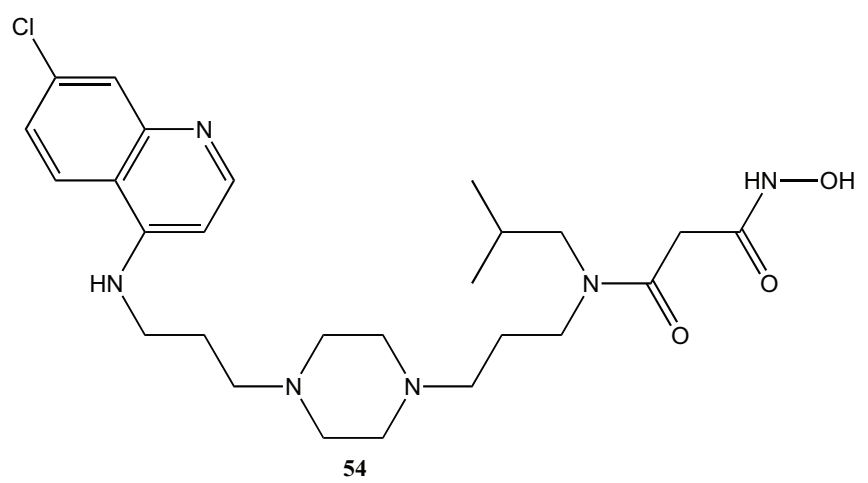

Fig. (39). The best quinoline-based inhibitor of PfA-M1developed by Deprez-Poulain's group [145].

\subsubsection{M17 Leucine-Aminopeptidase}

There is an overexpression of M17 leucine aminopeptidases (EC number: EC 3.4.11.1) in the malaria parasite; actually, the expression level of M17-family is $\sim 18$-fold higher than the M1-family [147, 148]. Leucine aminopeptidase (LAP) is an exopeptidase that has a preference for substrates which contain leucine or alanine in the $N$-terminus. Plasmodial LAP (PfLAP) exhibits its optimal activity at $\mathrm{pH} 7.2$ and is inactive below $\mathrm{pH} 6$, which is consistent with no activity in the FV. Apart from bestatin 50, other inhibitors of M17 leucine aminopeptidases have been reported [149, 150]. For instance, Gardiner and co-workers reported in 2007 a series of phosphinate dipeptide analogues as potential PfLAP inhibitors [150]. By screening different phosphinate analogues of dipeptides against functionally recombinant $P f L A P$, those authors were able to identify four compounds as potent inhibitors of the parasite PfLAP activity and from those four molecules, compounds 55, 56 displayed in (Fig. 40) presented the highest inhibitory effect against PfLAP. These two compounds resulted to be even more active than bestatin 50 against PfLAP and also showed activity against malaria parasite growth in culture in the low micromolar range. Docking of compound $\mathbf{5 5}$ against the enzyme showed that an amino group and two oxygen atoms are able to interact with the two zinc metal ions in the active site of PfLAP. In addition, the hydrophobic S1 in PfLAP can accommodate the hPhe of ligand $\mathbf{5 5}$. The affinity of compound $\mathbf{5 6}$ to PfLAP was significantly similar to that of $\mathbf{5 5}$ because the additional hydroxyl group from the Tyr residue is solvent exposed and does not promote additional interactions with the enzyme. Molecular docking studies showed that the phosphinic moieties in both $\mathbf{5 5}$ and $\mathbf{5 6}$ are able to form unique contacts with the metals ions and residue Lys386 of the enzyme's active site. These interactions do not occur with the corresponding fragment in bestatin and, therefore, can be accounted for the high binding affinity of 55 and $\mathbf{5 6}$ over bestatin $\mathbf{5 0}$ for 
PfLAP. Compound $\mathbf{5 5}$ was taken further to in vivo analysis using a non-lethal murine malaria model and the inhibitor $\mathbf{5 5}$ reduced the parasitemia of mice infected with $P$. chabaudi (reduction of parasite burden: 92\%) [150].
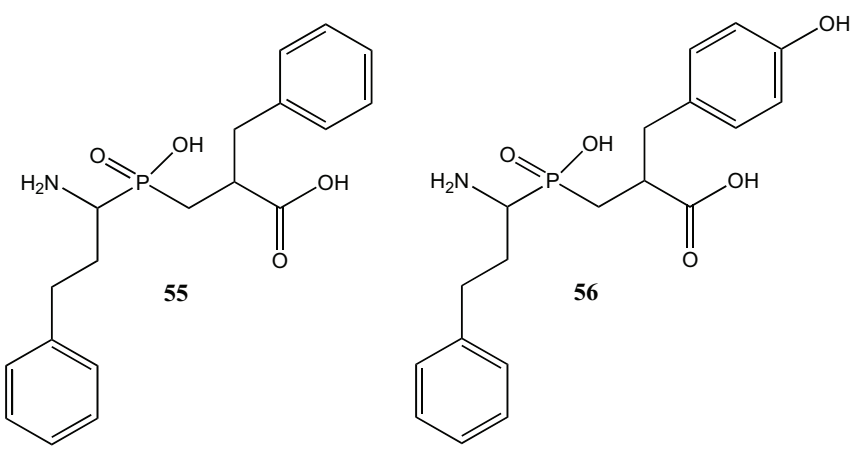

Fig. (40). PfLAP inhibitors identified by Gardiner and co-workers [150].

\section{CONCLUDING REMARKS}

Since the unveiling of the $P f$ genome, the number of targets to inhibit malaria parasite activity within host erythrocytes has increased, and there has been a great progress toward the development of new antimalarials. Still, malaria continues to be one of the most common chronic infectious diseases and a burden on developing nations, mainly due to the fast growing resistance of parasites to existing drugs. Plasmodial proteases which participate in the hemoglobin degradation have been found to be potential antimalarial targets since inhibition of this proteolytic process will impair parasite growth by starvation, and also would increase colloid-osmotic pressure within the infected erythrocyte causing its premature lysis. This review provides a general overview of the main proteases which participate in hemoglobin degradation currently being studied to, in time, suppress morbidity and mortality caused by malaria and prevent the progression of uncomplicated malaria to potentially fatal disease.

\section{CONFLICT OF INTEREST}

The author(s) confirm that this article content has no conflicts of interest.

\section{ACKNOWLEDGEMENTS}

We are grateful to Fundação para a Ciência e a Tecnologia (FCT, Portugal), FEDER and Programa COMPETE for the financial support through project PTDC/QUI-QUI/116 $864 / 2010$ and strategic projects PEst-C/QUI/UI0081/2011 and PEst-C/CTM/LA0011/2011. CT and JRBG thank FCT for the post-doctoral fellowship SFRH/BPD/62967/2009 and for Programa Ciência 2007, respectively. BP thanks FCT for the doctoral grant SFRH/BD/86166/2012.

\section{REFERENCES}

[1] Gallup, J.L.; Sachs, J.D., The economic burden of malaria. Am. J. Trop. Med. Hyg., 2001, 64(1-2 Suppl), 85-96

[2] Batista, R.; Silva Ade, J., Jr.; de Oliveira, A.B., Plant-derived antimalarial agents: new leads and efficient phytomedicines. Part II. Non-alkaloidal natural products. Molecules, 2009, 14(8), $3037-$ 3072 .
[3] Wiesner, J.; Ortmann, R.; Jomaa, H.; Schlitzer, M., New antimalarial drugs. Angew. Chem. Int. Ed. Engl., 2003, 42(43), 5274-5293.

[4] Sermwittayawong, N.; Singh, B.; Nishibuchi, M.; Sawangjaroen, N.; Vuddhakul, V., Human Plasmodium knowlesi infection in Ranong province, southwestern border of Thailand. Malaria J., 2012, 11,36 .

[5] Tang, T.-H.; Salas, A.; Ali-Tammam, M.; Martinez, M.; Lanza, M.; Arroyo, E.; Rubio, J., First case of detection of Plasmodium knowlesi in Spain by real time PCR in a traveller from Southeast Asia. Malaria J., 2010, 9(1), 219.

[6] Macreadie, I.; Ginsburg, H.; Sirawaraporn, W.; Tilley, L., Antimalarial drug development and new targets. Parasitol. Today, 2000, 16(10), 438-444.

[7] Whitty, C.J.M.; Rowland, M.; Sanderson, F.; Mutabingwa, T.K., Malaria. BMJ, 2002, 325(7374), 1221-1224.

[8] Greenwood, B.M.; Bojang, K.; Whitty, C.J.; Targett, G.A., Malaria. Lancet, 2005, 365(9469), 1487-1498.

[9] Chiang, P.K.; Bujnicki, J.M.; Su, X.; Lanar, D.E., Malaria: therapy, genes and vaccines. Curr. Mol. Med., 2006, 6(3), 309-326.

[10] Gardner, M.J.; Hall, N.; Fung, E.; White, O.; Berriman, M.; Hyman, R.W.; Carlton, J.M.; Pain, A.; Nelson, K.E.; Bowman, S.; Paulsen, I.T.; James, K.; Eisen, J.A.; Rutherford, K.; Salzberg, S.L.; Craig, A.; Kyes, S.; Chan, M.S.; Nene, V.; Shallom, S.J.; Suh, B.; Peterson, J.; Angiuoli, S.; Pertea, M.; Allen, J.; Selengut, J.; Haft, D.; Mather, M.W.; Vaidya, A.B.; Martin, D.M.; Fairlamb, A.H.; Fraunholz, M.J.; Roos, D.S.; Ralph, S.A.; McFadden, G.I.; Cummings, L.M.; Subramanian, G.M.; Mungall, C.; Venter, J.C.; Carucci, D.J.; Hoffman, S.L.; Newbold, C.; Davis, R.W.; Fraser, C.M.; Barrell, B., Genome sequence of the human malaria parasite Plasmodium falciparum. Nature, 2002, 419, (6906), 498-511.

[11] Andriantsoanirina, V.; Durand, R.; Pradines, B.; Baret, E.; Bouchier, C.; Ratsimbasoa, A.; Menard, D., In vitro susceptibility to pyrimethamine of DHFR I164L single mutant Plasmodium falciparum. Malaria J., 2011, 10, 283.

[12] Kompis, I.M.; Islam, K.; Then, R.L., DNA and RNA synthesis: antifolates. Chem. Rev., 2005, 105(2), 593-620.

[13] Tipsuwan, W.; Srichairatanakool, S.; Kamchonwongpaisan, S.; Yuthavong, Y.; Uthaipibull, C., Selection of drug resistant mutants from random library of Plasmodium falciparum dihydrofolate reductase in Plasmodium berghei model. Malaria J., 2011, 10, 119.

[14] Kelly, J.X.; Winter, R.W.; Braun, T.P.; Osei-Agyemang, M.; Hinrichs, D.J.; Riscoe, M.K., Selective killing of the human malaria parasite Plasmodium falciparum by a benzylthiazolium dye. Exp. Parasitol., 2007, 116(2), 103-110.

[15] Lisk, G.; Kang, M.; Cohn, J.V.; Desai, S.A., Specific inhibition of the plasmodial surface anion channel by dantrolene. Eukaryot. Cell, 2006, 5(11), 1882-1893.

[16] Quashie, N.B.; Ranford-Cartwright, L.C.; de Koning, H.P., Uptake of purines in Plasmodium falciparum-infected human erythrocytes is mostly mediated by the human equilibrative nucleoside transporter and the human facilitative nucleobase transporter. Malaria J., 2010, 9, 36.

[17] Bendale, P.; Olepu, S.; Suryadevara, P.K.; Bulbule, V.; Rivas, K.; Nallan, L.; Smart, B.; Yokoyama, K.; Ankala, S.; Pendyala, P.R.; Floyd, D.; Lombardo, L.J.; Williams, D.K.; Buckner, F.S.; Chakrabarti, D.; Verlinde, C.L.; Van Voorhis, W.C.; Gelb, M.H., Second generation tetrahydroquinoline-based protein farnesyltransferase inhibitors as antimalarials. J. Med. Chem., 2007, 50(19), 45854605.

[18] Fletcher, S.; Cummings, C.G.; Rivas, K.; Katt, W.P.; Horney, C.; Buckner, F.S.; Chakrabarti, D.; Sebti, S.M.; Gelb, M.H.; Van Voorhis, W.C.; Hamilton, A.D., Potent, Plasmodium-selective farnesyltransferase inhibitors that arrest the growth of malaria parasites: structure-activity relationships of ethylenediamine-analogue scaffolds and homology model validation. J. Med. Chem., 2008, 51(17), 5176-5197.

[19] Kohring, K.; Wiesner, J.; Altenkamper, M.; Sakowski, J.; Silber, K.; Hillebrecht, A.; Haebel, P.; Dahse, H.M.; Ortmann, R.; Jomaa, H.; Klebe, G.; Schlitzer, M., Development of benzophenone-based farnesyltransferase inhibitors as novel antimalarials. ChemMedChem, 2008, 3(8), 1217-1231.

[20] Olliaro, P.L.; Goldberg, D.E., The plasmodium digestive vacuole: metabolic headquarters and choice drug target. Parasitol. Today, 1995, 11(8), 294-297.

[21] Rosenthal, P.J., Proteases of malaria parasites: new targets for chemotherapy. Emerg. Infect. Dis., 1998, 4(1), 49-57. 
[22] Rosenthal, P.J.; Sijwali, P.S.; Singh, A.; Shenai, B.R., Cysteine proteases of malaria parasites: targets for chemotherapy. Curr. Pharm. Des., 2002, 8(18), 1659-1672.

[23] Goldberg, D.E.; Slater, A.F.; Cerami, A.; Henderson, G.B., Hemoglobin degradation in the malaria parasite Plasmodium falciparum: an ordered process in a unique organelle. Proc. Natl. Acad. Sci. USA, 1990, 87(8), 2931-2935.

[24] Lew, V.L.; Macdonald, L.; Ginsburg, H.; Krugliak, M.; Tiffert, T., Excess haemoglobin digestion by malaria parasites: a strategy to prevent premature host cell lysis. Blood Cells Mol. Dis., 2004, 32(3), 353-359.

[25] Lew, V.L.; Tiffert, T.; Ginsburg, H., Excess hemoglobin digestion and the osmotic stability of Plasmodium falciparum-infected red blood cells. Blood, 2003, 101(10), 4189-4194.

[26] Krugliak, M.; Zhang, J.; Ginsburg, H., Intraerythrocytic Plasmodium falciparum utilizes only a fraction of the amino acids derived from the digestion of host cell cytosol for the biosynthesis of its proteins. Mol. Biochem. Parasitol., 2002, 119(2), 249-256.

[27] Atamna, H.; Ginsburg, H., Origin of reactive oxygen species in erythrocytes infected with Plasmodium falciparum. Mol. Biochem. Parasitol., 1993, 61(2), 231-241.

[28] Francis, S.E.; Sullivan, D.J., Jr.; Goldberg, D.E., Hemoglobin metabolism in the malaria parasite Plasmodium falciparum. Annu. Rev. Microbiol., 1997, 51,97-123.

[29] Pagola, S.; Stephens, P.W.; Bohle, D.S.; Kosar, A.D.; Madsen, S.K., The structure of malaria pigment beta-haematin. Nature, 2000, 404(6775), 307-310

[30] Goldberg, D.E., Hemoglobin degradation. Curr. Top. Microbiol. Immunol., 2005, 295, 275-291.

[31] Liu, J.; Istvan, E.S.; Gluzman, I.Y.; Gross, J.; Goldberg, D.E., Plasmodium falciparum ensures its amino acid supply with multiple acquisition pathways and redundant proteolytic enzyme systems. Proc. Natl. Acad. Sci. USA, 2006, 103(23), 8840-8845.

[32] Naughton, J.A.; Nasizadeh, S.; Bell, A., Downstream effects of haemoglobinase inhibition in Plasmodium falciparum-infected erythrocytes. Mol. Biochem. Parasitol., 2010, 173(2), 81-87.

[33] Rosenthal, P.J. Antimalarial Chemotherapy: Mechanism of Action, Resistance, and New Directions in Drug Discovery. Human Press: New Jersey, 2001

[34] Ginsburg, H.; Tilley, L., Plasmodium falciparum metabolic pathways (MPMP) project upgraded with a database of subcellular locations of gene products. Trends Parasitol., 2011, 27(7), 285-286.

[35] Ersmark, K.; Feierberg, I.; Bjelic, S.; Hamelink, E.; Hackett, F.; Blackman, M.J.; Hulten, J.; Samuelsson, B.; Aqvist, J.; Hallberg, A., Potent inhibitors of the Plasmodium falciparum enzymes plasmepsin I and II devoid of cathepsin D inhibitory activity. J. Med. Chem., 2004, 47(1), 110-122.

[36] Gardiner, D.L.; Trenholme, K.R.; Skinner-Adams, T.S.; Stack, C.M.; Dalton, J.P., Overexpression of leucyl aminopeptidase in Plasmodium falciparum parasites. Target for the antimalarial activity of bestatin. J. Biol. Chem., 2006, 281(3), 1741-1745.

[37] Santos, M.M.; Moreira, R., Michael acceptors as cysteine protease inhibitors. Mini Rev. Med. Chem., 2007, 7(10), 1040-1050.

[38] Banerjee, R.; Liu, J.; Beatty, W.; Pelosof, L.; Klemba, M.; Goldberg, D.E., Four plasmepsins are active in the Plasmodium falciparum food vacuole, including a protease with an active-site histidine. Proc. Natl. Acad. Sci. USA, 2002, 99(2), 990-995.

[39] Coombs, G.H.; Goldberg, D.E.; Klemba, M.; Berry, C.; Kay, J.; Mottram, J.C., Aspartic proteases of Plasmodium falciparum and other parasitic protozoa as drug targets. Trends Parasitol., 2001, 17(11), 532-537.

[40] Bhaumik, P.; Gustchina, A.; Wlodawer, A., Structural studies of vacuolar plasmepsins. Biochim. Biophys. Acta, 2012, 1824(1), 207223.

[41] Dame, J.B.; Yowell, C.A.; Omara-Opyene, L.; Carlton, J.M.; Cooper, R.A.; Li, T., Plasmepsin 4, the food vacuole aspartic proteinase found in all Plasmodium spp. infecting man. Mol. Biochem. Parasitol., 2003, 130(1), 1-12.

[42] Nezami, A.; Freire, E., The integration of genomic and structural information in the development of high affinity plasmepsin inhibitors. Int. J. Parasitol., 2002, 32(13), 1669-1676.

[43] Andreeva, N.; Bogdanovich, P.; Kashparov, I.; Popov, M.; Stengach, M., Is histoaspartic protease a serine protease with a pepsinlike fold? Proteins, 2004, 55(3), 705-710.

[44] Bjelic, S.; Aqvist, J., Computational prediction of structure, substrate binding mode, mechanism, and rate for a malaria protease with a novel type of active site. Biochemistry, 2004, 43(46), 1452114528 .

[45] Bonilla, J.A.; Bonilla, T.D.; Yowell, C.A.; Fujioka, H.; Dame, J.B., Critical roles for the digestive vacuole plasmepsins of Plasmodium falciparum in vacuolar function. Mol. Microbiol., 2007, 65(1), 6475.

[46] Andrews, K.T.; Fairlie, D.P.; Madala, P.K.; Ray, J.; Wyatt, D.M.; Hilton, P.M.; Melville, L.A.; Beattie, L.; Gardiner, D.L.; Reid, R.C.; Stoermer, M.J.; Skinner-Adams, T.; Berry, C.; McCarthy, J.S., Potencies of human immunodeficiency virus protease inhibitors in vitro against Plasmodium falciparum and in vivo against murine malaria. Antimicrob. Agents Chemother., 2006, 50(2), 639648.

[47] Northrop, D.B., Follow the protons: a low-barrier hydrogen bond unifies the mechanisms of the aspartic proteases. Acc. Chem. Res., 2001, 34(10), 790-797.

[48] Parikh, S.; Gut, J.; Istvan, E.; Goldberg, D.E.; Havlir, D.V.; Rosenthal, P.J., Antimalarial activity of human immunodeficiency virus type 1 protease inhibitors. Antimicrob. Agents Chemother., 2005, 49(7), 2983-2985.

[49] Bott, R.; Subramanian, E.; Davies, D.R., Three-dimensional structure of the complex of the Rhizopus chinensis carboxyl proteinase and pepstatin at 2.5-A resolution. Biochemistry, 1982, 21(26), 6956-6962.

[50] James, M.N.; Sielecki, A.; Salituro, F.; Rich, D.H.; Hofmann, T., Conformational flexibility in the active sites of aspartyl proteinases revealed by a pepstatin fragment binding to penicillopepsin. Proc. Natl. Acad. Sci. USA, 1982, 79(20), 6137-6141.

[51] Asojo, O.A.; Afonina, E.; Gulnik, S.V.; Yu, B.; Erickson, J.W.; Randad, R.; Medjahed, D.; Silva, A.M., Structures of Ser205 mutant plasmepsin II from Plasmodium falciparum at $1.8 \mathrm{~A}$ in complex with the inhibitors rs367 and rs370. Acta Crystallogr. D Biol. Crystallogr., 2002, 58(Pt 12), 2001-2008.

[52] Beyer, B.B.; Johnson, J.V.; Chung, A.Y.; Li, T.; Madabushi, A.; Agbandje-McKenna, M.; McKenna, R.; Dame, J.B.; Dunn, B.M., Active-site specificity of digestive aspartic peptidases from the four species of Plasmodium that infect humans using chromogenic combinatorial peptide libraries. Biochemistry, 2005, 44(6), 17681779 .

[53] Dahlgren, A.; Kvarnstrom, I.; Vrang, L.; Hamelink, E.; Hallberg, A.; Rosenquist, A.; Samuelsson, B., Solid-phase library synthesis of reversed-statine type inhibitors of the malarial aspartyl proteases plasmepsin I and II. Bioorg. Med. Chem., 2003, 11(6), 827-841.

[54] Dahlgren, A.; Kvarnstrom, I.; Vrang, L.; Hamelink, E.; Hallberg, A.; Rosenquist, A.; Samuelsson, B., New inhibitors of the malaria aspartyl proteases plasmepsin I and II. Bioorg. Med. Chem., 2003, $11(16), 3423-3437$.

[55] Ersmark, K.; Feierberg, I.; Bjelic, S.; Hulten, J.; Samuelsson, B.; Aqvist, J.; Hallberg, A., C2-symmetric inhibitors of Plasmodium falciparum plasmepsin II: synthesis and theoretical predictions. Bioorg. Med. Chem., 2003, $11(17), 3723-3733$.

[56] Johansson, P.O.; Chen, Y.; Belfrage, A.K.; Blackman, M.J.; Kvarnstrom, I.; Jansson, K.; Vrang, L.; Hamelink, E.; Hallberg, A.; Rosenquist, A.; Samuelsson, B., Design and synthesis of potent inhibitors of the malaria aspartyl proteases plasmepsin I and II. Use of solid-phase synthesis to explore novel statine motifs. J. Med. Chem., 2004, 47(13), 3353-3366.

[57] Johansson, P.O.; Lindberg, J.; Blackman, M.J.; Kvarnstrom, I.; Vrang, L.; Hamelink, E.; Hallberg, A.; Rosenquist, A.; Samuelsson, B., Design and synthesis of potent inhibitors of plasmepsin I and II: X-ray crystal structure of inhibitor in complex with plasmepsin II. J. Med. Chem., 2005, 48(13), 4400-4409.

[58] Kiso, A.; Hidaka, K.; Kimura, T.; Hayashi, Y.; Nezami, A.; Freire, E.; Kiso, Y., Search for substrate-based inhibitors fitting the S2' space of malarial aspartic protease plasmepsin II. J. Pept. Sci., 2004, 10(11), 641-647.

[59] Li, T.; Yowell, C.A.; Beyer, B.B.; Hung, S.H.; Westling, J.; Lam, M.T.; Dunn, B.M.; Dame, J.B., Recombinant expression and enzymatic subsite characterization of plasmepsin 4 from the four Plasmodium species infecting man. Mol. Biochem. Parasitol., 2004, 135(1), 101-109.

[60] Nezami, A.; Kimura, T.; Hidaka, K.; Kiso, A.; Liu, J.; Kiso, Y.; Goldberg, D.E.; Freire, E., High-affinity inhibition of a family of Plasmodium falciparum proteases by a designed adaptive inhibitor. Biochemistry, 2003, 42(28), 8459-8464. 
[61] Noteberg, D.; Hamelink, E.; Hulten, J.; Wahlgren, M.; Vrang, L.; Samuelsson, B.; Hallberg, A., Design and synthesis of plasmepsin I and plasmepsin II inhibitors with activity in Plasmodium falciparum-infected cultured human erythrocytes. J. Med. Chem., 2003, 46(5), 734-746.

[62] Noteberg, D.; Schaal, W.; Hamelink, E.; Vrang, L.; Larhed, M., High-speed optimization of inhibitors of the malarial proteases plasmepsin I and II. J. Comb. Chem., 2003, 5(4), 456-464.

[63] Oscarsson, K.; Oscarson, S.; Vrang, L.; Hamelink, E.; Hallberg, A.; Samuelsson, B., New potent C2-symmetric malaria plasmepsin I and II inhibitors. Bioorg. Med. Chem., 2003, 11(7), 1235-1246.

[64] Romeo, S.; Dell'Agli, M.; Parapini, S.; Rizzi, L.; Galli, G.; Mondani, M.; Sparatore, A.; Taramelli, D.; Bosisio, E., Plasmepsin II inhibition and antiplasmodial activity of Primaquine-Statine 'double-drugs'. Bioorg. Med. Chem. Lett., 2004, 14(11), 2931-2934.

[65] Tsuchiya, Y.; Hidaka, K.; Kiso, A.; Kimura, T.; Hayashi, Y.; Nezami, A.; Freire, E.; Kiso, Y., Evaluation of peptidomimetic inhibitors against malarial protease plasmepsin. Peptide Science, 2005, 41, 527-530.

[66] Carroll, C.D.; Johnson, T.O.; Tao, S.; Lauri, G.; Orlowski, M.; Gluzman, I.Y.; Goldberg, D.E.; Dolle, R.E., Evaluation of a structure-based statine cyclic diamino amide encoded combinatorial library against plasmepsin II and cathepsin D. Bioorg. Med. Chem. Lett., 1998, 8(22), 3203-3206.

[67] Carroll, C.D.; Patel, H.; Johnson, T.O.; Guo, T.; Orlowski, M.; He, Z.M.; Cavallaro, C.L.; Guo, J.; Oksman, A.; Gluzman, I.Y.; Connelly, J.; Chelsky, D.; Goldberg, D.E.; Dolle, R.E., Identification of potent inhibitors of Plasmodium falciparum plasmepsin II from an encoded statine combinatorial library. Bioorg. Med. Chem. Lett., 1998, 8(17), 2315-2320.

[68] Gosh, A.; Mannhold, R.; Kubinyi, H.; Folkers, G. Aspartic acid proteases as therapeutic targets. Wiley $\mathrm{VCH}, \mathbf{2 0 1 0}$

[69] Haque, T.S.; Skillman, A.G.; Lee, C.E.; Habashita, H.; Gluzman, I.Y.; Ewing, T.J.; Goldberg, D.E.; Kuntz, I.D.; Ellman, J.A., Potent, low-molecular-weight non-peptide inhibitors of malarial aspartyl protease plasmepsin II. J. Med. Chem., 1999, 42(8), 14281440 .

[70] Caldera, P.S.; Yu, Z.; Knegtel, R.M.; McPhee, F.; Burlingame, A.L.; Craik, C.S.; Kuntz, I.D.; Ortiz de Montellano, P.R., Alkylation of a catalytic aspartate group of the SIV protease by an epoxide inhibitor. Bioorg. Med. Chem., 1997, 5(11), 2019-2027.

[71] Gupta, D.; Yedidi, R.S.; Varghese, S.; Kovari, L.C.; Woster, P.M., Mechanism-based inhibitors of the aspartyl protease plasmepsin II as potential antimalarial agents. J. Med. Chem., 2010, 53(10), 4234-4247.

[72] Zutshi, R.; Chmielewski, J., Targeting the dimerization interface for irreversible inhibition of HIV-1 protease. Bioorg. Med. Chem. Lett., 2000, 10(17), 1901-1903.

[73] Binkert, C.; Frigerio, M.; Jones, A.; Meyer, S.; Pesenti, C.; Prade, L.; Viani, F.; Zanda, M., Replacement of isobutyl by trifluoromethyl in pepstatin A selectively affects inhibition of aspartic proteinases. ChemBioChem, 2006, 7(1), 181-186.

[74] Ersmark, K.; Samuelsson, B.; Hallberg, A., Plasmepsins as potential targets for new antimalarial therapy. Med. Res. Rev., 2006, 26(5), 626-666.

[75] Boss, C.; Richard-Bildstein, S.; Weller, T.; Fischli, W.; Meyer, S.; Binkert, C., Inhibitors of the Plasmodium falciparum parasite aspartic protease plasmepsin II as potential antimalarial agents. Curr. Med. Chem., 2003, 10(11), 883-907.

[76] Oefner, C.; Binggeli, A.; Breu, V.; Bur, D.; Clozel, J.P.; D'Arcy, A.; Dorn, A.; Fischli, W.; Gruninger, F.; Guller, R.; Hirth, G.; Marki, H.; Mathews, S.; M, M.1.; Ridley, R.G.; Stadler, H.; Vieira, E.; Wilhelm, M.; Winkler, F.; Wostl, W., Renin inhibition by substituted piperidines: a novel paradigm for the inhibition of monomeric aspartic proteinases? Chem. Biol., 1999, 6(3), 127-131.

[77] Boss, C.; Corminboeuf, O.; Grisostomi, C.; Weller, T., Inhibitors of aspartic proteases, Äì potential antimalarial agents. Expert Opinion on Therapeutic Patents, 2006, 16(3), 295-317.

[78] Corminboeuf, O.; Dunet, G.; Hafsi, M.; Grimont, J.; Grisostomi, C.; Meyer, S.; Binkert, C.; Bur, D.; Jones, A.; Prade, L.; Brun, R.; Boss, C., Inhibitors of Plasmepsin II-potential antimalarial agents. Bioorg. Med. Chem. Lett., 2006, 16(24), 6194-6199.

[79] Prade, L.; Jones, A.F.; Boss, C.; Richard-Bildstein, S.; Meyer, S.; Binkert, C.; Bur, D., X-ray structure of plasmepsin II complexed with a potent achiral inhibitor. J. Biol. Chem., 2005, 280(25), 23837-23843.
[80] Blum, A.; Bottcher, J.; Sammet, B.; Luksch, T.; Heine, A.; Klebe, G.; Diederich, W.E., Achiral oligoamines as versatile tool for the development of aspartic protease inhibitors. Bioorg. Med. Chem., 2008, 16(18), 8574-8586.

[81] Teixeira, C.; Gomes, J.R.B.; Gomes, P., Falcipains, Plasmodium falciparum cysteine proteases as key drug targets against malaria. Curr. Med. Chem., 2011, 18(10), 1555-1572.

[82] Eksi, S.; Czesny, B.; Greenbaum, D.C.; Bogyo, M.; Williamson, K.C., Targeted disruption of Plasmodium falciparum cysteine protease, falcipain 1 , reduces oocyst production, not erythrocytic stage growth. Mol. Microbiol., 2004, 53(1), 243-250.

[83] Kerr, I.D.; Lee, J.H.; Pandey, K.C.; Harrison, A.; Sajid, M.; Rosenthal, P.J.; Brinen, L.S., Structures of falcipain-2 and falcipain-3 bound to small molecule inhibitors: implications for substrate specificity. J. Med. Chem., 2009, 52(3), 852-857.

[84] Sijwali, P.S.; Kato, K.; Seydel, K.B.; Gut, J.; Lehman, J.; Klemba, M.; Goldberg, D.E.; Miller, L.H.; Rosenthal, P.J., Plasmodium falciparum cysteine protease falcipain-1 is not essential in erythrocytic stage malaria parasites. Proc. Natl. Acad. Sci. USA, 2004, 101(23), 8721-8726.

[85] Nielsen, K.M.; Kasper, J.; Choi, M.; Bedford, T.; Kristiansen, K.; Wirth, D.F.; Volkman, S.K.; Lozovsky, E.R.; Hartl, D.L., Gene conversion as a source of nucleotide diversity in Plasmodium falciparum. Mol. Biol. Evol., 2003, 20(5), 726-734.

[86] Ettari, R.; Bova, F.; Zappala, M.; Grasso, S.; Micale, N., Falcipain2 inhibitors. Med. Res. Rev., 2010, 30(1), 136-167.

[87] Klemba, M.; Goldberg, D.E., Biological roles of proteases in parasitic protozoa. Annu. Rev. Biochem., 2002, 71, 275-305.

[88] Subramanian, S.; Hardt, M.; Choe, Y.; Niles, R.K.; Johansen, E.B.; Legac, J.; Gut, J.; Kerr, I.D.; Craik, C.S.; Rosenthal, P.J., Hemoglobin cleavage site-specificity of the Plasmodium falciparum cysteine proteases falcipain-2 and falcipain-3. PLoS ONE, 2009, 4(4), e5156.

[89] Kerr, I.D.; Lee, J.H.; Farady, C.J.; Marion, R.; Rickert, M.; Sajid, M.; Pandey, K.C.; Caffrey, C.R.; Legac, J.; Hansell, E.; McKerrow, J.H.; Craik, C.S.; Rosenthal, P.J.; Brinen, L.S., Vinyl sulfones as antiparasitic agents and a structural basis for drug design. J. Biol. Chem., 2009, 284(38), 25697-25703.

[90] Gibbons, P.; Verissimo, E.; Araujo, N.C.; Barton, V.; Nixon, G.L.; Amewu, R.K.; Chadwick, J.; Stocks, P.A.; Biagini, G.A.; Srivastava, A.; Rosenthal, P.J.; Gut, J.; Guedes, R.C.; Moreira, R.; Sharma, R.; Berry, N.; Cristiano, M.L.; Shone, A.E.; Ward, S.A.; O'Neill, P.M., Endoperoxide carbonyl falcipain $2 / 3$ inhibitor hybrids: toward combination chemotherapy of malaria through a single chemical entity. J. Med. Chem., 2010, 53(22), 8202-8206.

[91] Lee, B.J.; Singh, A.; Chiang, P.; Kemp, S.J.; Goldman, E.A.; Weinhouse, M.I.; Vlasuk, G.P.; Rosenthal, P.J., Antimalarial activities of novel synthetic cysteine protease inhibitors. Antimicrob. Agents Chemother., 2003, 47(12), 3810-3814.

[92] Ettari, R.; Micale, N.; Schirmeister, T.; Gelhaus, C.; Leippe, M.; Nizi, E.; Di Francesco, M.E.; Grasso, S.; Zappalà, M., Novel peptidomimetics containing a vinyl ester moiety as highly potent and selective falcipain-2 inhibitors. J. Med. Chem., 2009, 52(7), 21572160.

[93] Ettari, R.; Nizi, E.; Di Francesco, M.E.; Dude, M.A.; Pradel, G.; Vicik, R.; Schirmeister, T.; Micale, N.; Grasso, S.; Zappalà, M., Development of peptidomimetics with a vinyl sulfone warhead as irreversible falcipain-2 inhibitors. J. Med. Chem., 2008, 51(4), 988996.

[94] Desai, P.V.; Patny, A.; Gut, J.; Rosenthal, P.J.; Tekwani, B.; Srivastava, A.; Avery, M., Identification of novel parasitic cysteine protease inhibitors by use of virtual screening. 2. The available chemical directory. J. Med. Chem., 2006, 49(5), 1576-1584.

[95] Desai, P.V.; Patny, A.; Sabnis, Y.; Tekwani, B.; Gut, J.; Rosenthal, P.; Srivastava, A.; Avery, M., Identification of novel parasitic cysteine protease inhibitors using virtual screening. 1. The ChemBridge database. J. Med. Chem., 2004, 47(26), 6609-6615.

[96] Li, H.; Huang, J.; Chen, L.; Liu, X.; Chen, T.; Zhu, J.; Lu, W.; Shen, X.; Li, J.; Hilgenfeld, R.; Jiang, H., Identification of novel falcipain-2 inhibitors as potential antimalarial agents through structure-based virtual screening. J. Med. Chem., 2009, 52(15), 49364940 .

[97] Powers, J.C.; Asgian, J.L.; Ekici, O.D.; James, K.E., Irreversible inhibitors of serine, cysteine, and threonine proteases. Chem. Rev., 2002, 102(12), 4639-4750. 
[98] Schulz, F.; Gelhaus, C.; Degel, B.; Vicik, R.; Heppner, S.; Breuning, A.; Leippe, M.; Gut, J.; Rosenthal, P.J.; Schirmeister, T. Screening of protease inhibitors as antiplasmodial agents. Part I: Aziridines and epoxides. ChemMedChem, 2007, 2(8), 1214-1224.

[99] Breuning, A.; Degel, B.; Schulz, F.; Buchold, C.; Stempka, M. Machon, U.; Heppner, S.; Gelhaus, C.; Leippe, M.; Leyh, M. Kisker, C.; Rath, J.; Stich, A.; Gut, J.; Rosenthal, P.J.; Schmuck, C.; Schirmeister, T., Michael acceptor based antiplasmodial and antitrypanosomal cysteine protease inhibitors with unusual amino acids. J. Med. Chem., 2010, 53(5), 1951-1963.

[100] Rosenthal, P.J.; Olson, J.E.; Lee, G.K.; Palmer, J.T.; Klaus, J.L.; Rasnick, D., Antimalarial effects of vinyl sulfone cysteine proteinase inhibitors. Antimicrob. Agents Chemother., 1996, 40(7), 16001603.

[101] Shenai, B.R.; Lee, B.J.; Alvarez-Hernandez, A.; Chong, P.Y.; Emal, C.D.; Neitz, R.J.; Roush, W.R.; Rosenthal, P.J., Structureactivity relationships for inhibition of cysteine protease activity and development of Plasmodium falciparum by peptidyl vinyl sulfones. Antimicrob. Agents Chemother., 2003, 47(1), 154-160.

[102] Teixeira, C.; Gomes, J.R.B.; Couesnon, T.; Gomes, P., Molecular docking and 3D-quantitative structure activity relationship analyses of peptidyl vinyl sulfones: Plasmodium falciparum cysteine proteases inhibitors. J. Comput. Aided. Mol. Des., 2011, 25(8), 763-775.

[103] Ehmke, V.; Kilchmann, F.; Heindl, C.; Cui, K.; Huang, J.; Schirmeister, T.; Diederich, F., Peptidomimetic nitriles as selective inhibitors for the malarial cysteine protease falcipain-2. MedChemComm, 2011, 2(8), 800-804.

[104] Micale, N.; Kozikowski, A.P.; Ettari, R.; Grasso, S.; Zappala, M.; Jeong, J.J.; Kumar, A.; Hanspal, M.; Chishti, A.H., Novel peptidomimetic cysteine protease inhibitors as potential antimalarial agents. J. Med. Chem., 2006, 49(11), 3064-3067.

[105] Pérez, B.; Teixeira, C.; Figueiras, M.; Gut, J.; Rosenthal, P.J.; Gomes, J.R.B.; Gomes, P., Novel cinnamic acid/4-aminoquinoline conjugates bearing non-proteinogenic amino acids: towards the development of potential dual action antimalarials. Eur. J. Med. Chem., 2012, 54, 887-899.

[106] Zhu, S.; Hudson, T.H.; Kyle, D.E.; Lin, A.J., Synthesis and in vitro studies of novel pyrimidinyl peptidomimetics as potential antimalarial therapeutic agents. J. Med. Chem., 2002, 45(16), 3491-3496.

[107] Verissimo, E.; Berry, N.; Gibbons, P.; Cristiano, M.L.; Rosenthal, P.J.; Gut, J.; Ward, S.A.; O'Neill, P.M., Design and synthesis of novel 2-pyridone peptidomimetic falcipain $2 / 3$ inhibitors. Bioorg. Med. Chem. Lett., 2008, 18(14), 4210-4214.

[108] Valente, C.; Guedes, R.C.; Moreira, R.; Iley, J.; Gut, J.; Rosenthal, P.J., Dipeptide vinyl sultams: synthesis via the Wittig-Horner reaction and activity against papain, falcipain-2 and Plasmodium falciparum. Bioorg. Med. Chem. Lett., 2006, 16(15), 4115-4119.

[109] Glória, P.M.C.; Gut, J.; Gonçalves, L.M.; Rosenthal, P.J.; Moreira, R.; Santos, M.M.M., Aza vinyl sulfones: Synthesis and evaluation as antiplasmodial agents. Bioorg. Med. Chem., 2011, 19(24), 76357642 .

[110] Kumar, S.P.; Glória, P.M.C.; Gonçalves, L.M.; Gut, J.; Rosenthal, P.J.; Moreira, R.; Santos, M.M.M., Squaric acid: a valuable scaffold for developing antimalarials? MedChemComm, 2012, 3(4), 489-493

[111] Kumar, S.P.; Gut, J.; Guedes, R.C.; Rosenthal, P.J.; Santos, M.M.M.; Moreira, R., Design, synthesis and evaluation of 3methylene-substituted indolinones as antimalarials. Eur. J. Med. Chem., 2011, 46(3), 927-933

[112] Moon, R.P.; Tyas, L.; Certa, U.; Rupp, K.; Bur, D.; Jacquet, C.; Matile, H.; Loetscher, H.; Grueninger-Leitch, F.; Kay, J.; Dunn, B.M.; Berry, C.; Ridley, R.G., Expression and characterisation of plasmepsin I from Plasmodium falciparum. Eur. J. Biochem., 1997, 244(2), 552-560.

[113] Dziadulewicz, E.K.; Brown, M.C.; Dunstan, A.R.; Lee, W.; Said, N.B.; Garratt, P.J., The design of non-peptide human bradykinin B2 receptor antagonists employing the benzodiazepine peptidomimetic scaffold. Bioorg. Med. Chem. Lett., 1999, 9(3), 463468

[114] Eguchi, M.; Kahn, M., Design, synthesis, and application of peptide secondary structure mimetics. Mini Rev. Med. Chem., 2002, 2(5), 447-462

[115] Capela, R.; Oliveira, R.; Gonçalves, L.M.; Domingos, A.; Gut, J.; Rosenthal, P.J.; Lopes, F.; Moreira, R., Artemisinin-dipeptidyl vinyl sulfone hybrid molecules: design, synthesis and preliminary
SAR for antiplasmodial activity and falcipain-2 inhibition. Bioorg. Med. Chem. Lett., 2009, 19(12), 3229-3232.

[116] Rosenthal, P.J.; McKerrow, J.H.; Aikawa, M.; Nagasawa, H.; Leech, J.H., A malarial cysteine proteinase is necessary for hemoglobin degradation by Plasmodium falciparum. J. Clin. Invest., 1988, 82(5), 1560-1566.

[117] Micale, N.; Ettari, R.; Schirmeister, T.; Evers, A.; Gelhaus, C.; Leippe, M.; Zappala, M.; Grasso, S., Novel 2H-isoquinolin-3-ones as antiplasmodial falcipain-2 inhibitors. Bioorg. Med. Chem., 2009, 17(18), 6505-6511.

[118] Coteron, J.M.; Catterick, D.; Castro, J.; Chaparro, M.J.; Diaz, B.; Fernandez, E.; Ferrer, S.; Gamo, F.J.; Gordo, M.; Gut, J.; de las Heras, L.; Legac, J.; Marco, M.; Miguel, J.; Munoz, V.; Porras, E.; de la Rosa, J.C.; Ruiz, J.R.; Sandoval, E.; Ventosa, P.; Rosenthal, P.J.; Fiandor, J.M., Falcipain inhibitors: optimization studies of the 2-pyrimidinecarbonitrile lead series. J. Med. Chem., 2010, 53(16), 6129-6152.

[119] Marrero-Ponce, Y.; Iyarreta-Veitía, M.; Montero-Torres, A.; Romero-Zaldivar, C.; Brandt, C.A.; Ávila, P.E.; Kirchgatter, K.; Machado, Y., Ligand-based virtual screening and in silico design of new antimalarial compounds using nonstochastic and stochastic total and atom-type quadratic maps. J. Chem. Inf. Model., 2005, 45(4), 1082-1100.

[120] Shah, F.; Gut, J.; Legac, J.; Shivakumar, D.; Sherman, W.; Rosenthal, P.J.; Avery, M.A., Computer-aided drug design of falcipain inhibitors: virtual screening, structure-activity relationships, hydration site thermodynamics, and reactivity analysis. J. Chem. Inf. Model., 2012, 52(3), 696-710.

[121] Shah, F.; Mukherjee, P.; Gut, J.; Legac, J.; Rosenthal, P.J.; Tekwani, B.L.; Avery, M.A., Identification of novel malarial cysteine protease inhibitors using structure-based virtual screening of a focused cysteine protease inhibitor library. J. Chem. Inf. Model., 2011, $51(4), 852-864$

[122] Guantai, E.M.; Ncokazi, K.; Egan, T.J.; Gut, J.; Rosenthal, P.J.; Bhampidipati, R.; Kopinathan, A.; Smith, P.J.; Chibale, K., Enoneand chalcone-chloroquinoline hybrid analogues: in silico guided design, synthesis, antiplasmodial activity, in vitro metabolism, and mechanistic studies. J. Med. Chem., 2011, 54(10), 3637-3649.

[123] Guantai, E.M.; Ncokazi, K.; Egan, T.J.; Gut, J.; Rosenthal, P.J.; Smith, P.J.; Chibale, K., Design, synthesis and in vitro antimalarial evaluation of triazole-linked chalcone and dienone hybrid compounds. Bioorg. Med. Chem., 2010, 18(23), 8243-8256.

[124] Shah, F.; Wu, Y.; Gut, J.; Pedduri, Y.; Legac, J.; Rosenthal, P.J.; Avery, M.A., Design, synthesis and biological evaluation of novel benzothiazole and triazole analogs as falcipain inhibitors. MedChem Comm, 2011, 2(12), 1201-1207.

[125] Micale, N.; Cinellu, M.A.; Maiore, L.; Sannella, A.R.; Severini, C.; Schirmeister, T.; Gabbiani, C.; Messori, L., Selected gold compounds cause pronounced inhibition of Falcipain 2 and effectively block P. falciparum growth in vitro. J. Inorg. Biochem., 2011, 105(12), 1576-1579.

[126] Singh, N.; Sijwali, P.S.; Pandey, K.C.; Rosenthal, P.J., Plasmodium falciparum: biochemical characterization of the cysteine protease falcipain-2'. Exp. Parasitol., 2006, 112(3), 187-192.

[127] Murata, C.E.; Goldberg, D.E., Plasmodium falciparum falcilysin: a metalloprotease with dual specificity. J. Biol. Chem., 2003, 278(39), 38022-38028.

[128] Eggleson, K.K.; Duffin, K.L.; Goldberg, D.E., Identification and characterization of falcilysin, a metallopeptidase involved in hemoglobin catabolism within the malaria parasite Plasmodium falciparum. J. Biol. Chem., 1999, 274(45), 32411-32417.

[129] Ponpuak, M.; Klemba, M.; Park, M.; Gluzman, I.Y.; Lamppa, G.K.; Goldberg, D.E., A role for falcilysin in transit peptide degradation in the Plasmodium falciparum apicoplast. Mol. Microbiol., 2007, 63(2), 314-334.

[130] Wang, F.; Krai, P.; Deu, E.; Bibb, B.; Lauritzen, C.; Pedersen, J.; Bogyo, M.; Klemba, M., Biochemical characterization of Plasmodium falciparum dipeptidyl aminopeptidase 1. Mol. Biochem. Parasitol., 2011, 175(1), 10-20.

[131] Klemba, M.; Gluzman, I.; Goldberg, D.E., A Plasmodium falciparum dipeptidyl aminopeptidase I participates in vacuolar hemoglobin degradation. J. Biol. Chem., 2004, 279(41), 43000-43007.

[132] Methot, N.; Guay, D.; Rubin, J.; Ethier, D.; Ortega, K.; Wong, S.; Normandin, D.; Beaulieu, C.; Reddy, T.J.; Riendeau, D.; Percival, M.D., In vivo inhibition of serine protease processing requires a 
high fractional inhibition of cathepsin C. Mol. Pharmacol., 2008, 73(6), 1857-1865

[133] Methot, N.; Rubin, J.; Guay, D.; Beaulieu, C.; Ethier, D.; Reddy, T.J.; Riendeau, D.; Percival, M.D., Inhibition of the activation of multiple serine proteases with a cathepsin $\mathrm{C}$ inhibitor requires sustained exposure to prevent pro-enzyme processing. J. Biol. Chem., 2007, 282(29), 20836-20846.

[134] Deu, E.; Leyva, M.J.; Albrow, V.E.; Rice, M.J.; Ellman, J.A Bogyo, M., Functional studies of Plasmodium falciparum dipeptidyl aminopeptidase I using small molecule inhibitors and active site probes. Chem. Biol., 2010, 17(8), 808-819.

[135] Skinner-Adams, T.S.; Stack, C.M.; Trenholme, K.R.; Brown, C.L.; Grembecka, J.; Lowther, J.; Mucha, A.; Drag, M.; Kafarski, P.; McGowan, S.; Whisstock, J.C.; Gardiner, D.L.; Dalton, J.P., Plasmodium falciparum neutral aminopeptidases: new targets for antimalarials. Trends Biochem. Sci., 2010,35(1), 53-61.

[136] Bradshaw, R.A.; Brickey, W.W.; Walker, K.W., N-terminal processing: the methionine aminopeptidase and $\mathrm{N}$ alpha-acetyl transferase families. Trends Biochem. Sci., 1998, 23(7), 263-267.

[137] Griffith, E.C.; Su, Z.; Turk, B.E.; Chen, S.; Chang, Y.H.; Wu, Z.; Biemann, K.; Liu, J.O., Methionine aminopeptidase (type 2) is the common target for angiogenesis inhibitors AGM-1470 and ovalicin. Chem. Biol., 1997, 4(6), 461-471.

[138] Zhang, P.; Nicholson, D.E.; Bujnicki, J.M.; Su, X.; Brendle, J.J. Ferdig, M.; Kyle, D.E.; Milhous, W.K.; Chiang, P.K., Angiogenesis inhibitors specific for methionine aminopeptidase 2 as drugs for malaria and leishmaniasis. J. Biomed. Sci., 2002, 9(1), 34-40.

[139] Gavigan, C.S.; Dalton, J.P.; Bell, A., The role of aminopeptidases in haemoglobin degradation in Plasmodium falciparum-infected erythrocytes. Mol. Biochem. Parasitol., 2001, 117(1), 37-48.

[140] Allary, M.; Schrevel, J.; Florent, I., Properties, stage-dependent expression and localization of Plasmodium falciparum M1 family zinc-aminopeptidase. Parasitology, 2002, 125 (Pt 1), 1-10.

[141] Flipo, M.; Beghyn, T.; Leroux, V.; Florent, I.; Deprez, B.P.; Deprez-Poulain, R.F., Novel selective inhibitors of the zinc plasmodial aminopeptidase PfA-M1 as potential antimalarial agents. $J$. Med. Chem., 2007, 50(6), 1322-1334.

[142] Jones, P.M.; Robinson, M.W.; Dalton, J.P.; George, A.M., The Plasmodium falciparum malaria M1 alanyl aminopeptidase (PfAM1): insights of catalytic mechanism and function from MD simulations. PLOS ONE, 2011, 6(12), e28589.

[143] McGowan, S.; Porter, C.J.; Lowther, J.; Stack, C.M.; Golding, S.J.; Skinner-Adams, T.S.; Trenholme, K.R.; Teuscher, F.; Donnelly,
S.M.; Grembecka, J.; Mucha, A.; Kafarski, P.; Degori, R.; Buckle, A.M.; Gardiner, D.L.; Whisstock, J.C.; Dalton, J.P., Structural basis for the inhibition of the essential Plasmodium falciparum M1 neutral aminopeptidase. Proc. Natl. Acad. Sci. USA, 2009, 106(8), 2537-2542.

[144] Velmourougane, G.; Harbut, M.B.; Dalal, S.; McGowan, S.; Oellig, C.A.; Meinhardt, N.; Whisstock, J.C.; Klemba, M.; Greenbaum, D.C., Synthesis of new (-)-bestatin-based inhibitor libraries reveals a novel binding mode in the S1 pocket of the essential malaria M1 metalloaminopeptidase. J. Med. Chem., 2011, 54(6), 1655-1666.

[145] Flipo, M.; Florent, I.; Grellier, P.; Sergheraert, C.; Deprez-Poulain, R., Design, synthesis and antimalarial activity of novel, quinolinebased, zinc metallo-aminopeptidase inhibitors. Bioorg. Med. Chem. Lett., 2003, 13(16), 2659-2662.

[146] Grembecka, J.; Mucha, A.; Cierpicki, T.; Kafarski, P., The most potent organophosphorus inhibitors of leucine aminopeptidase. Structure-based design, chemistry, and activity. J. Med. Chem., 2003, 46(13), 2641-2655.

[147] Curley, G.P.; O'Donovan, S.M.; McNally, J.; Mullally, M.; O'Hara, H.; Troy, A.; O'Callaghan, S.A.; Dalton, J.P., Aminopeptidases from Plasmodium falciparum, Plasmodium chabaudi chabaudi and Plasmodium berghei. J. Eukaryot. Microbiol., 1994, 41(2), 119123.

[148] Zheng, W.; Zhai, Q.; Sun, J.; Li, C.B.; Zhang, L.; Li, H.; Zhang, X.; Li, S.; Xu, Y.; Jiang, H.; Wu, X.; Li, C., Bestatin, an inhibitor of aminopeptidases, provides a chemical genetics approach to dissect jasmonate signaling in Arabidopsis. Plant. Physiol., 2006, 141(4), 1400-1413.

[149] Maric, S.; Donnelly, S.M.; Robinson, M.W.; Skinner-Adams, T.; Trenholme, K.R.; Gardiner, D.L.; Dalton, J.P.; Stack, C.M.; Lowther, J., The M17 leucine aminopeptidase of the malaria parasite Plasmodium falciparum: importance of active site metal ions in the binding of substrates and inhibitors. Biochemistry, 2009, $48(23), 5435-5439$.

[150] Skinner-Adams, T.S.; Lowther, J.; Teuscher, F.; Stack, C.M.; Grembecka, J.; Mucha, A.; Kafarski, P.; Trenholme, K.R.; Dalton, J.P.; Gardiner, D.L., Identification of phosphinate dipeptide analog inhibitors directed against the Plasmodium falciparum M17 leucine aminopeptidase as lead antimalarial compounds. J. Med. Chem., 2007, 50(24), 6024-6031. 